\title{
MASTER
}

WAPD-TM-191

AEC RESEARCH AND DEVELOPMENT REPORT

\section{ISOTOPIC CONCENTRATIONS FOR A TIME-VARYING IRRADIATION OF URANIUM OR PLUTONIUM}

AUGUST 1959

CONTRACT AT-11-1-GEN-14

BETTIS PLANT-PITTSBURGH, PA. OPERATED FOR THE U.S. ATOMIC ENERGY COMMISSION BY BETTIS ATOMIC POWER DIVISION, WESTINGHOUSE ELECTRIC CORPORATION 


\section{DISCLAIMER}

This report was prepared as an account of work sponsored by an agency of the United States Government. Neither the United States Government nor any agency Thereof, nor any of their employees, makes any warranty, express or implied, or assumes any legal liability or responsibility for the accuracy, completeness, or usefulness of any information, apparatus, product, or process disclosed, or represents that its use would not infringe privately owned rights. Reference herein to any specific commercial product, process, or service by trade name, trademark, manufacturer, or otherwise does not necessarily constitute or imply its endorsement, recommendation, or favoring by the United States Government or any agency thereof. The views and opinions of authors expressed herein do not necessarily state or reflect those of the United States Government or any agency thereof. 


\section{DISCLAIMER}

Portions of this document may be illegible in electronic image products. Images are produced from the best available original document. 
UC-34: Physics and Mathematics

\section{ISOTOPIC CONCENTRATIONS FOR A TIME-VARYING IRRADIATION OF URANIUM OR PLUTONIUM}

S. B. Gunst

\section{Contract AT-11-1-GEN-14}

August 1959

Price $\$ 1.25$

Available from the Office of Technical Services,

Department of Commerce,

Washington 25, D. C.

This document is an interim memorandum prepared primarily for internal reference and does not represent a final expression of the opinion of Westinghouse. When this memorandum is distributed externally, it is with the express understanding that Westinghouse makes no representation as to completeness, accuracy, or usability of information contained therein.

\section{BETTIS PLANT - PITTSBURGH, PA. OPERATED FOR THE U.S. ATOMIC ENERGY COMMISSION BY BETTIS ATOMIC POWER DIVISION, WESTINGHOUSE ELECTRIC CORPORATION}


This report was prepared as an account of Government sponsored work. Heither the United States, nor the Commission, nor any person acting on hehalf of the Commission:

A. Makes any warranty or representation, expressed or implied, with respect to the accuracy, completeness, or usefulness of the information contained in this report, or that the use of any information, apparatus, method, or process disclosed in this report may not infringe privately owned rights; or

B. Assumes any liabilities with respect to the use of, or for damages resultina from the use of any information, apparatus, method, or process disclosed in this report.

. As used in the above, "person acting on behalf of the Commission" includes any emoloye or contractor of the commission, or employe of such contractor, to the extent that such employe or contractor of the Commicsion, or omoloyo of ouoh contractor orepnres, disseminates, or provides access to, any information pursuant to his employment or contract with the Commission, or his employment with such contractor. 
CONTENTS

Page No.

ISOTOPIC NUMBER DENSITY AND FISSION EXPRESSIONS

QUANTITIES RELATED TO THE NUMBER DENSITIES

CODE DETAILS

4

RECOMMENDED CODE REVISION TO MINIMIZE ROUND-OFF ERRORS

CONCLUSION

APPENDIX A: EXPRESSIONS FOR ISOTOPIC NUMBER DENSITY AND QUANTITIES DERIVABLE THEREFROM

APPENDIX B: DETAILS OF THE S0269 CODE -

APPENDLX C: REVISED EXPRESSIONS FOR ISOTOPIC NUMBER DENSITY AND

APPENDIX D: MODIFIED FLUX-TIME CODE S0264

APPENDIX E: S0306 CODE, EXTENSION OF S0269 CODE, FOR IRRADIATION HISTORY STEPS OTHER THAN THE FIRST

ACKNOWLEDGMENTS

36

REFERENCES 
Expressions for isotopic concentrations as functions of irradiation are derived for uranium and plutonium having any initial isotopic composition. Fourteen isotopes including nine heavy elements and five fission products are considered. The decay of certain isotopes with half lives in the range from two hours to 13.2 years is taken into account as is the specific time-varying irradiation history. The expressions presented are applicable to any irradiation described by a succession of steps during which the thermal flux and epithermal flux are constant for each step but may vary from step to step. Expressions are also presented for quantities related to the isotopic concentrations including (1) the number of fissions in each fissionable isotope during each irradiation step: (2) the corresponding megawatt days per ton (of fuel initially present): (3) the accumulated fissions and megawatt days per ton, both isotopic and total; (4) the thermal, epithermal, and total conversion ratios present at the end of each irradiation step; and (5) the fractional changes in both $\eta$ and $\eta f$ as a result of irradiation and as functions of time after removal from. the high flux. A code for the Bell Interpretive System on the $18 M-650$ digital computer is described for the calculation of the isotopic concentrations and the related quantities.

\section{ISOTOPIC CONCENTRATIONS FOR A TIME -VARYING IRRADIATION OF URANIUM OR PLUTONIUM}

\section{S. B. Gunst}

The calculation of long-term reactivity changes in reactor fuels requires the solution of differential equations for the concentrations of all isotopes significant to the reactivity. To simplify the solutions, assumptions are ordinarily made. For example, isotopes of short half life are commonly assumed to have infinite decay constants which implies that their daughter isotopes are formed instantly, isotopes of long half life are assumed to be stable, and the ratio of epithermal-to-thermal flux is assumed to be constant throughout irradiation. Under such conditions, the isotopic concentrations depend not upon the true, detailed irradiation history but upon the total time-integrated thermal flux and the constant epithermal-to-thermal flux ratio. They do not depend explicitly upon time but rather upon the flux-time product. The expressions for isotopic concentration are particularly simple and involve initial (pre-irradiation) concentrations only. An exposure of any magnitude is treated as a single flux-time step; and the isotopic concentrations as a function of irradiation are obtained by solutions for steps of various total flux-times.

Although solutions based on such assumptions* have been useful in theoretical calculations, there are serious limitations:

1) The assumption that neutron capture in U-238 yields Pu-239 instantly is shown (Ref 1) to introduce an error in the calculated reactivity for irradiated natural uranium that may be as large as $2 \%$.

2) The assumption of a constant ratio for the epithermal-to-thermal flux is unrealistic in many cases-e.g., the blanket of the Shippingport reactor in which the spatial power distribution, particularly close to the seed, changes over the lifetime. This ratio may vary severalfold for irradiations of more than one cycle in a facility such as the Materials Testing Reactor (MTR) where there are changes in loading from cycle to cycle.

3) The concentrations of short-lived isotopes and their daughter isotopes are particularly sensitive to variations in the irradiation history which occur over time intervals comparable to

* Work done by J. C. Connor of Bettis Atomic Power Division on the calculation of isotopic changes in irradiated uranium fuel specimens, January 1958. 
the half lives. The concentrations of the fission products $\mathrm{Xe}-135, \mathrm{Sm}-149$, and their precursors, for example, are strongly dependent upon the detailed history.

4). If irradiated specimens are measured in a critical facility such as the Reactivity Measurement Facility (RMF) '(Ref 2); within a few hours after irradiation, decaying isotopes will influence the measurement as will the detailed irradiation history prior to removal from the high flux.

To circumvent such limitations, isotopic-concentration calculations should take into account the decay of certain short-lived isotopes as well as the true, detailed irradiation history. A numberdensity code (S0269 for the Bell Interpretive System on the IBM-650 digital computer) for uranium and/or plutonium is described which, for any thermal and epithermal flux history, computes the isotopic number densities for nine heavy isotopes in two chains (U-235, U-236, U-237, Np-237; $\mathrm{U}-238, \mathrm{~Np}-239, \mathrm{Pu}-239, \mathrm{Pu}-240, \mathrm{Pu}-241$ ), and five fission-product isotopes in two mass chains (I-235, Xe-135; Nd-149, Pm-149, Sm-149). Although the decay of 23.5-minute U-239 and 2-minute Te-1 35 (precursors of Np-239 and I-135, respectively) is assumed to be instantaneous, the code specifically provides for the decay of 6.75-day U-237, 2.33-day Np-239, 13.2-year Pu-241, 6.68hour I-135, 9.13-hour Xe-135, 2-hour Nd-149, and 53-hour Pm-149. How each of these might influence the reactivity in any irradiation history of interest may be deduced from code results.

For this program, the irradiation history is described by successive steps during which the thermal and eipthermal fluxes are constant for each step, but may vary from step to step. A stepwise history is essentially realized in irradiation facilities such as the MTR; and in principle, any irradiation history may be approximated as closely as desired by steps.

Initial number densities for each of the fourteen isotopes mentioned may have arbitrary magnitude since the expressions give the number densities at the end of a step based upon (1) the number densities at the start of the step, (2) the time duration of the step, (3) the thermal flux and epithermalto-thermal flux ratio during the step, and (4) the neutron interaction parameters appropriate for the step. Number densities are computed for an irradiation history consisting of any number of successive steps.

\section{ISOTOPIC NUMBER DENSITY AND FISSION EXPRESSIONS}

For heavy elements, the general expression for the time rate of change in the concentration $\mathrm{N}^{\mathrm{i}}, \mathbf{j}$ of an isotope having atomic number $\mathbf{i}$ and atomic weight $j$ is

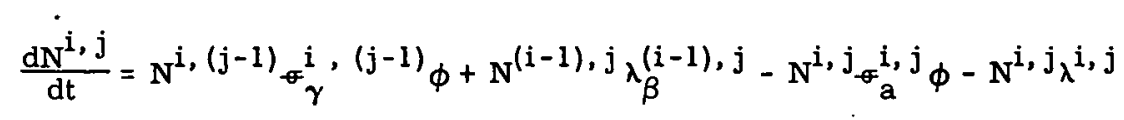

where $t$ is the time, $\phi$ is the thermal flux, $\lambda_{\beta}$ is a disintegration constant for $\beta^{-}$emission, and $\lambda$ is a total disintegration constant. Each concentration $\mathrm{N}^{i, j}$ is the number of atoms of a given isotope per unit volume. The quantities $\sigma_{\gamma}^{i, j}$ and $\epsilon_{a}^{i} j$ are the total effective capture and absorption cross sections for 1sotope 1, $j$ and include thermal and epithermal effects. By definition,

$$
F_{\gamma}^{i, j} \equiv \bar{\sigma}_{\gamma^{\prime}}^{i, j}+\frac{\phi_{R}}{\phi} R_{\gamma}^{i, j}
$$

and

$$
\mho_{a}^{i, j} \equiv \bar{\sigma}_{a}^{i, j}+\frac{\phi_{R}}{\phi} R_{a}^{i, j}+\delta^{i, j}
$$

where the subscripts $\gamma$ and a refer to capture and absorption, respectively; $\bar{\sigma}^{i, j}$ is the effective thermal cross section, $R^{i, j}$ is the effective epithermal (not epicadmium) resonance integral, $\phi_{R}$ is the epithermal flux per unit lethargy for an-epithermal distribution which is inversely proportional to the energy, and $\delta^{i, j}$ accounts for fast fission under the provision that $\delta^{i, j} \phi$ gives the probability 
for fast-fission per unit time and per atom. The expressions tacitly assume that fast fission, epithermal absorption, and epithermal capture are proportional to the thermal flux during each irradiation step, even though they may vary from step to step.

In Eq (1) the first term on the right accounts for production by neutron capture, the second for production by $\beta^{-}$decay, the third for loss by neutron capture, and the fourth for loss by decay. Production by other processes such as alpha emission, $(n, 2 n),(n, d)$, and (n, $p)$ is considered to be negligible. In integral form, Eq (1) may be written

$$
N^{i, j}=e^{-\psi^{i, j}} \int\left[N^{i,(j-1)}{ }_{\gamma}^{i,(j-1)} \phi+N^{(i-1), j} \lambda_{\beta}^{(i-1), j}\right] e^{\psi^{i, j_{t}}} d t+c e^{-\psi^{i, j}}
$$

where

$$
\psi^{i, j}=\sigma_{a}^{i, j} \phi+\lambda^{i, j}
$$

and $c$ is an integration constant which may be evaluated by imposing the initial conditions.

For fission products, a term for production by fission must beladded, and Eq (4) takes the form

$$
\begin{aligned}
N^{i, j} & =e^{-\psi^{i, j}} \int\left[N^{i,(j-1)} \sigma_{\gamma}^{-i,(j-1)} \phi+N^{(i-1), j_{\lambda}(i-1), j}\right. \\
& \left.\left.+\sum_{u, v} y_{i, j}^{u, v} N^{u, v}{ }_{a}^{u, v}-\sigma_{\gamma}^{u, v}\right) \phi\right] e^{\psi^{i, j}} d t+c e^{-\psi^{i, j}},
\end{aligned}
$$

where the last term in the brackets is the production by fission in fissionable isotope $u, v$ (of atomic number $u$ and atomic weight $v$ ), having effective fission cross section $\left(\sigma_{a}^{u, v}--_{\gamma}^{u, v}\right)$ and a yield $y_{i, j}^{u, v}$ for the fission-product isotope $i, j$ from the fission of isotope $u, v$. The summation includes all fissionable isotopes $u, v$.

For the $k^{\text {th }}$ irradiation step of duration $t_{k}$, subscripts $k$ should be attached to the quantities in Eqs (4), (5), and (6) which, though constant during any one step, may vary from one step to another* . At the end of the $k^{\text {th }}$ irradiation step, the number density is described by $\mathrm{N}_{k}^{i, j}$; while at the start of the $\mathrm{k}^{\text {th }}$ step, it is designated $\mathrm{N}_{\mathrm{k}-1}^{\mathrm{j}, \mathrm{j}}$. The steps run successively, with no interruption for intervals during which the specimen is out-of-pile, since such intervals are described by steps for which the flux is zero.

The solutions of Eq (4) for the nine heavy isotopes are given in Eqs (A1) through (A9) in Appendix A. Fast fission is accounted for in U-238 only. To obtain expressions for the fission-product concentrations, it is first necessary to derive expressions for the number of fissions $F_{k}^{u, v}$ of isotope $u, v$ during the $k^{\text {th }}$ irradiation step. Exact expressions for $F_{k}^{u, v}$ are given in Eqs (Al0) through (A13) in Appendix A.

The Eqs (A1) through (A13) illustrate the increasing complexity of the algebra in expressions for the higher isotopes. Exact expressions for fission-product concentrations would, therefore, become prohibitively long. Expressions of reasonable length may be obtained by approximating the production from fission. If the fission rate in each fissionable isotope is assumed to be constant during any irradiation step $\mathrm{k}$, the summation term in $\mathrm{Eq}(6)$ becomes a constant and may be written

$$
\sum_{u, v} y_{i, j}^{u, v}\left(F_{k}^{u, v} / t_{k}\right)
$$

* Although the subscripts $\mathrm{k}$ were intentionally omitted in Eqs (4), (5), and (6) to avoid confusion, they are included in the equations in the appendices. 
where $F_{k}^{u, v} / t_{k}$ is the average fission rate during the step. The number-density equations for the five fission products may then be derived readily and are given in Eqs (A14) through (A18) in

Appendix A. Despite the assumption of constant fission rates during each irradiation step, the number densities for the fission products may, in principle, be computed as accurately as desired by dividing each step into any number of shorter steps. The expressions for the heavy isotopes and the number of fissions remain exact:

For a step $k$ in which the thermal flux $\phi_{k}$ is zero, Eqs (Al) through (A18) reduce to Eqs (Al9) through (A36).

\section{QUANTITIES RELATED TO THE NUMBER DENSITIES}

Solutions for the isotopic number densities and the number of fissions in each isotope facilitate the evaluation of other important quantities. The number of fissions during the $\mathrm{k}^{\text {th }}$ step leads to the energy density (isotopic or total) in megawatt days/ton of heavy isotopes (MWD/T). The accumulated MWD/T (isotopic or total) for all irradiation steps from the start of irradiation is then obtained trivlally by addition. 'l'he expressions for MWD/T are given in Eqs (A37) through (A4l) in Appendix A.

Expressions for the thermal, epithermal, and total conversion ratios are given in Eqs (A42) through (A44).

The regeneration factor $\eta$ (the number of fission neutrons produred per thermal neitron absorbod) for the material within the fuel volume (including fission products but excluding cladding and moderator) is given in Eq (A45). The quantity $\eta f$, where $f$ is thermal utilization, is also given by Eq (A45) provided this expression now includes the effects of cladding and moderator. Since reactivity measurements may be made in a different facility than that in which specimens are irradiated, the neutron interaction parameters appropriate to the spectrum of the measurement facility (or any desired spectrum) may be used for each isotope in the expressions for $\eta$ and $\eta f$. Thus, the parameters may differ as desired from those appropriate for the irradiation history.

\section{CODE DETAILS}

Input and Output

The following information concerning the S0269 code appears in Appendix B:

1) Memory locations for the 166 input parameters needed and for the four quantities which describe each specific step in the irradiation history

2) Output locations

3) Reproduction of the code.

Almost all of the thousand available memory locations are used in the code. Although some consolidation could be accomplished by certain revisions, the operating time saved woild not justify the effort required for the revision.

The four quantities which describe a step in the irradiation are an index number $j$ whose function will be described, the elapsed time $t$ of the step, the thermal-neutron flux $\phi$, and the epithermal-tothermal flux ratio $\phi_{R} / \phi$. The computer stops when there are no further irradiation-history steps to be read.

\section{Parameter Adjustments Based on Concentrations}

It was intended that the values of effective cross sections and resonance integrals used in the code calculations could be adjusted within the code to account for changes in these quantities as a result of irradiation-induced changes in isotopic concentrations. For this reason the subscript $\mathrm{k}$ for the $\mathrm{k}^{\text {th }}$ step is attached to these quantities in the expressions in the appendices. Although there is 
nothing in the code to prevent incorporation of suitable adjustment methods, the lack of sufficient memory locations precludes such adjustment in this specific code. Appendix $\mathbf{E}$ gives an alternative adjustment method.

Calculated Output

Reactivity measurements on a specimen irradiated in a high-flux facility are made during periods in which the specimen is out-of-pile. Consequently, the reactivity transient (associated with Xe-135, $\mathrm{Sm}-149, \mathrm{Pu}-239$, and $\mathrm{Pu}-241$ ) is present during the time of measurement*. The transient behavior of $\eta$ and $\eta$ following each cycle of irradiation is calculated for 20 selected cooling times, or times after discharge from the high flux, covering any time range desired. These transient calculations have no influence on the number densities computed for the true irradiation history, but do give the transient behavior which would be expected during any shutdown interval if the specimen were to remain out-of-pile throughout the period of this transient.

An index number $\mathrm{j}$ is assigned to each irradiation history step and is used to control certain code computations including the transient calculations:

1) For all values of $j$ (and $\phi$ ), the code punches (in locations 196 to 210 ) the accumulated fluxtime summed over $k$ steps and the isotopic number densities present at the end of the $k^{\text {th }}$ step. It also punches (in locations 822 to 827 ) the elapsed time of the step, the thermal flux $\phi$ during the step, and the average isotopic fission rates during the step.

2) For $\mathrm{j}$ and $\phi$ both nonzero, used to describe the last irradiation step prior to specimen discharge for reactivity measurement, the code punches additional output as follows:

a) In locations 907 to 912 , the code punches the accumulated flux-time summed over $k$ steps with the corresponding number of fissions, both isotopic and total.

b) In locations 970 to 975 , the code punches the accumulated flux-time summed over $\mathrm{k}$ steps and the corresponding energy density (MWD/T) for each isotope and all isotopes.

c) In locations 919 to 923 , the code punches the accumulated flux-time summed over $\mathrm{k}$ steps, the epithermal-to-thermal flux ratio $\phi_{R} / \phi$ for the $k^{\text {th }}$ step only, and the thermal, epithermal, and total conversion ratios prevalent at the end of this step.

3) For $j \neq 0$ and $\phi=0$, used to describe a shutdown interval during which reactivity measurements are taken, the code computes the isotopic number densities present at the end of the step and stores these for use in the subsequent irradiation history calculations.

a) For $j=20$ and $\phi=0$, the code also computes the reactivity transient for the 20 selected cooling times entered as input in locations 151 to 170. For each of these cooling times, the code punches (in locations 901 to 906) the accumulated flux-time summed over $\mathbf{k}$ steps, the epithermal-to-thermal flux ratio averaged over $k$ steps, the accumulated $\mathrm{MWD} / \mathrm{T}$, the cooling time, the fractional change $\Delta \eta / \eta_{0}$ in the regeneration factor relative to a non-irradiated specimen, and the fractional change $\Delta(\eta f) /(\eta f)_{0}$. For the last of these cooling times, the code also punches (in locations 924 to 940 ) the accumulated flux-time summed over $\mathrm{k}$ steps and the isotopic number densities which would be present after this last cooling time. Thus, the so-called "asymptotic" number densities for a long cooling time may be avallable (for all 1sotopes except 13.2-year Pu-241).

* Although the "asymptotic" reactivity could be essentially attained by taking the measurements 200 or more hours after discharge, much irradiation time would be lost by imposing such a restriction since the down-time for refueling the MTR, for example, is usually only 50 to 100 hours. To measure the asymptotic reactivity, the specimen would remain out-of-pile during the succeeding irradiation interval. 
b) For $j=1$ and $\phi=0$, the code punches the data described in locations 901 to 906 and 924 to 940 for the last of the cooling times only. This case gives only "asymptotic" values for the number densities, $\Delta \eta / \eta_{0}$ and $\Delta(\eta f) /(\eta f)_{0}$.

Despite the many quantities calculated, the code is basically a number-density code for any specified irradiation history. The other quantities computed require only moderate additional computer time and are of particular interest to users of the code.

Round-off Errors

The floating-point decimal notation employed in the Bell Interpretative System permits no more than eight-digit significance in a single calculation. Round-off errors may, therefore, become appreciable, particularly in the case of subtraction of two quantities which are nearly equal. The possibility of encountering such difficulties in the present code has been investigated and the following conclusions made:

1) Calculations for the case of zero flux [expressions (A19) through (A36) in Appendix A] are satisfactory (round-off error, if any, is in seventh or eighth significant figure) for any step time equal to or greater than 100 seconds. This time is a practical lower limit for the time of a zero-flux step in irradiations of interest.

2) Calculations for the case of nonzero flux [expressions (Al) through (A18) in Appendix A] have round-off errors which depend upon the magnitude of the flux-time product. Provided each flux-time step exceeds $3 \times 10^{19} \mathrm{n} / \mathrm{cm}^{2}$, the round-off error is negligible (estimated to be less than $0.2 \%$ for the isotopic concentrations for exposures in the range from $3 \times 10^{19}$ to $\left.10^{22} \mathrm{n} / \mathrm{cm}^{2}\right)$.

If the true irradiation history includes steps for which the flux-time product is less than $3 \times 10^{19} \mathrm{n} / \mathrm{cm}^{2}$, the limitation (2) requires that the true history be somewhat modified. The S0264 Code for the Bell Interpretive System takes the true history as input* and computes a modified history in which the flux-time product of each step exceeds $3 \times 10^{19} \mathrm{n} / \mathrm{cm}^{2}$. A brief description of this code appears in Appendix D.

Although the true history is modified in the S0264 Code, both.the total elapsed time and total flux-time are preserved. Calculated concentrations for isotopes influenced primarily by long-term effects, therefore, would be expected to be nearly the same for both the modified and true irradiation histories; however, the calculated concentrations for isotopes influenced by short-term effects may not be the same. In particular, for true flux-time steps less than $3 \times 10^{19} \mathrm{n} / \mathrm{cm}^{2}$ (40 hours in a flux of $2 \times 10^{14} \mathrm{n} / \mathrm{cm}^{2}-\mathrm{sec}$ ), the modified history will not give the true concentrations for the short-lived isotopes I-135, Xe-135, and $\mathrm{Nd}-149$. The transient during a zero-flux step in the modified history is, therefore, reliable only if it is preceded by a true step in which the flux-time product exceeds $3 \times 10^{19} \mathrm{n} / \mathrm{cm}^{2}$. This situation is realized in most experimental cases of interest.

Errors in Fission-Product Concentrations Introduced by the Use of Average Fission Rates

Although flux-time steps larger than $3 \times 10^{19} \mathrm{n} / \mathrm{cm}^{2}$ give negligible round-off errors, much larger flux-time steps will introduce an error in the fission-product concentrations if the fission rate near the end of an irradiation step differs markedly from the average fission rate during the step, a situation which would occur if the concentration of a fissionable isotope were to change appreciably during the step. If an upper limit for a flux-time step of $10^{20} \mathrm{n} / \mathrm{cm}^{2}$ is imposed, the error in

* Input for the S0264 Code may be obtained from the detailed irradiation history provided by the S0216 Code, input for which is obtained from the S0215 and S0226 Codes. The S0226 Code, written by $E$. D. McGarry, is used for the processing of flux-monitor measurements to give the average time-integrated thermal flux and the ratio of epithermal-to-thermal flux for each cycle of irradiation. The S0215 and S0216 Codes were written by J. C. Connor and provide the true irradiation history of a specimen. 
fission-product concentrations, resulting from the assumption of constant fission rate during the step, is estimated to be less than $2 \%$. This error would be virtually independent of the number of steps in an irradiation because the five specific fission products considered attain equilibrium concentrations essentially during each irradiation step.

The maximum flux-time step is an input parameter (location 146). If it is set at $10^{20} \mathrm{n} / \mathrm{cm}^{2}$, the code divides larger flux-time steps into as many equal steps as are needed to make each step $\leq 10^{20} \mathrm{n} / \mathrm{cm}^{2}$. Thus, each flux-time step within the code lies between $3 \times 10^{19}$ and $10^{20} \mathrm{n} / \mathrm{cm}^{2}$, although the input flux-time steps may have any magnitude greater than $3 \times 10^{19} \mathrm{n} / \mathrm{cm}^{2}$.

\section{RECOMMENDED CODE REVISION TO MINIMIZE ROUND-OFF ERRORS}

As described previously, round-off errors could be appreciable for a small flux-time step. To obviate this difficulty, a modified irradiation history is used. The true irradiation history could be used if the basic number density and fission expressions were rewritten. The expressions of Appendix A, which contain numerous differences of exponentials, all reduce to expressions containing simple summations. Expressions for the change in isotopic number density during the $\mathrm{k}^{\text {th }}$ step are derived, from which the number density at the end of the step may be obtained trivially as desired. This procedure is consistent with the objective of minimizing round-off errors. Expressions ( $\mathrm{Cl}$ ) through (C45) in Appendix $\mathrm{C}$ are revised expressions corresponding to (A1) through (A36) in Appendix A.

A code for the Bell Interpretive System on the IBM-650 digital computer has been written based on the revised expressions. The machine-computation time proves to be long, and would be more reasonable if the code were written in machine language for a more advanced computer.

In the revised code, a convergence criterion for the summations requires that the $n^{\text {th }}$ or last computed term contribute less than a given fraction to the sum (say $10^{-9}$ for eight-digit accuracy). Round-off errors associated with small flux-time steps become negligible. However, if a $\psi t$ term in a sum is large $(>10)$, corresponding to a large flux-time or time step, round-off errors again may become troublesome because terms in a sum may become very large before the sum begins to converge. As shown in Eq (5), $\psi \mathrm{t}$ includes both absorption and decay. Evidently, what is needed is a code which evaluates exponentials (see expressions of Appendix A) for large flux-time steps and all zero-flux steps, and evaluates summations (see expressions of Appendix C) for small flux-time steps. The preparation and use of such a code for the IBM-704, for example, would give high computational accuracy and reasonable running time. Number densities would be computed for the specific measured irradiation history rather than for a modified history as is done in the present S0269 code.

\section{CONCLUSION}

It may be argued that high precision in the calculation of number densities is not justified heranse of the many uncertainties in the fission and absorption parameters needed for the calculations. This may be true; however, if theory and experiment are to be compared, uncertainties in the theoretical calculations should depend only upon uncertainties in parameters and not upon errors introduced by code or computer limitations. Only then will it be meaningful to examine parameters and adjust their magnitudes in order to bring theory and experiment into agreement.

While the present 50269 code is very useful, it should be regarded as an interim code to be replaced by the superior code to be written, as described in the previous section, for a faster computer. 
EXPRESSIONS FOR ISOTOPIC NUMBER DENSITY AND QUANTITIES DERIVABLE THEREFROM

Superscripts $25,26,27,37,28,39,49,40,41, I, X e, N d, P m$, and Sm refer to U-235, U-236, U-237, Np-237, U-238, Np-239, Pu-239, Pu-240, Pu-241, I-135, Xe-135, Nd-149, Pm-149, and $\mathrm{Sm}-149$, respectively. For all decaying isotopes considered, total decay constants appear because $\lambda_{\beta}=\lambda$.

Heavy-Element Number Densities

$$
\begin{aligned}
& N_{k}^{25}=N_{k-1}^{25} e^{-\psi_{k}^{25} t_{k}} \\
& N_{k}^{26}=\frac{N_{k-1}^{25}-\gamma_{k}^{25} \phi_{k}}{\psi_{k}^{26}-\psi_{k}^{25}}\left[e^{-\psi_{k}^{25} t_{k}}-e^{-\psi_{k}^{26} t_{k}}\right]+N_{k-1}^{26} e^{-\psi_{k}^{26} t_{k}}
\end{aligned}
$$

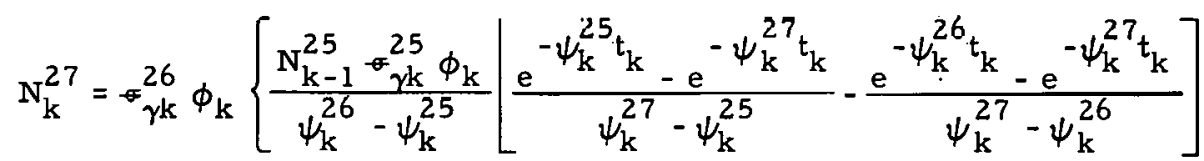

$$
\begin{aligned}
& \left.+\frac{N_{k-1}^{26}}{\psi_{k}^{27}-\psi_{k}^{26}}\left[e^{-\psi_{k}^{26} t_{k}}-e^{-\psi_{k}^{27} t_{k}}\right]\right\}+N_{k-1}^{27} e^{-\psi_{k}^{27} t_{k}} \\
& N_{k}^{37}=\lambda^{27}\left\{\sigma _ { \gamma k } ^ { 2 6 } \phi _ { k } \left\{\frac { N _ { k - 1 } ^ { 2 5 } \psi _ { \gamma k } ^ { 2 5 } } { \psi _ { k } ^ { 2 6 } - \psi _ { k } ^ { 2 5 } } \left[\frac{1}{\psi_{k}^{27}-\psi_{k}^{25}}\left(\frac{e^{-\psi_{k}^{25} t_{k}}-e^{-\psi_{k}^{37} t_{k}}}{\psi_{l k}^{37}-\psi_{k}^{25}}-\frac{e^{-\psi_{k}^{27} t_{k}}-e^{-\psi_{k}^{37} t_{k}}}{\psi_{k}^{37}-\psi_{k}^{27}}\right)\right.\right.\right. \\
& \left.-\frac{1}{\psi_{k}^{27}-\psi_{k}^{36}}\left(\frac{e^{-\psi_{k}^{26} t_{k}}-e^{-\psi_{k}^{37} t_{k}}}{\psi_{k}^{37}-\psi_{k}^{26}}-\frac{e^{26} t_{k}^{27}-e^{-\psi_{k}^{37} t_{k}}}{\psi_{k}^{37}-\psi_{k}^{27}}\right)\right] \\
& \left.+\frac{N_{k}^{26}}{\psi_{k}^{27}-\psi_{k}^{26}}\left[\frac{e^{-\psi_{k}^{26} t_{k}}-e^{-\psi_{k}^{37} t_{k}}}{\psi_{k}^{37}-\psi_{k}^{26}}-\frac{e^{-\psi_{k}^{27} t_{k}}-e^{-\psi_{k}^{37} t_{k}}}{\psi_{k}^{37}-\psi_{k}^{27}}\right]\right\} \\
& \left.+\frac{N_{k-1}^{27}}{\psi_{k}^{37}-\psi_{k}^{27}}\left[c^{-\psi_{k}^{26} t_{k}}-e^{-\psi_{k}^{37} t_{k}}\right]\right\}+N_{k-1}^{37} e^{-\psi_{k}^{37} t_{k}} \\
& \mathrm{~N}_{k}^{28}=\mathrm{N}_{\mathrm{k}-1}^{28} \mathrm{e}^{-\psi_{\mathrm{k}}^{28} \mathrm{t}_{\mathrm{k}}}
\end{aligned}
$$




$$
\begin{aligned}
& N_{k}^{39}=\frac{N_{k-1}^{28}{ }^{28} \phi_{k}}{\psi_{k}^{39}-\psi_{k}^{28}}\left[e^{-\psi_{k}^{28} t_{k}}-e^{-\psi_{k}^{39} \cdot t_{k}}\right]+N_{k-1}^{39} e^{-\psi_{k}^{39} t_{k}}
\end{aligned}
$$

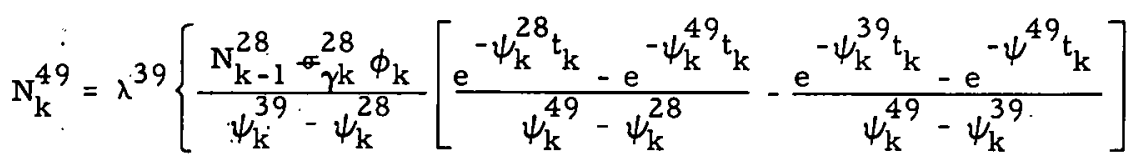

$$
\begin{aligned}
& \left.+\frac{\mathrm{N}_{\mathrm{k}-1}^{39}}{\psi_{\mathrm{k}}^{49}-\psi_{\mathrm{k}}^{39}}\left[\mathrm{e}^{-\psi_{\mathrm{k}}^{39} \mathrm{t}_{\mathrm{k}}}-\mathrm{e}^{-\psi_{\mathrm{k}}^{49} \mathrm{t}_{\mathrm{k}}}\right]\right\}+\mathrm{N}_{\mathrm{k}-1}^{49} \mathrm{e}^{-\psi_{\mathrm{k}}^{49} \mathrm{t}_{\mathrm{k}}}
\end{aligned}
$$

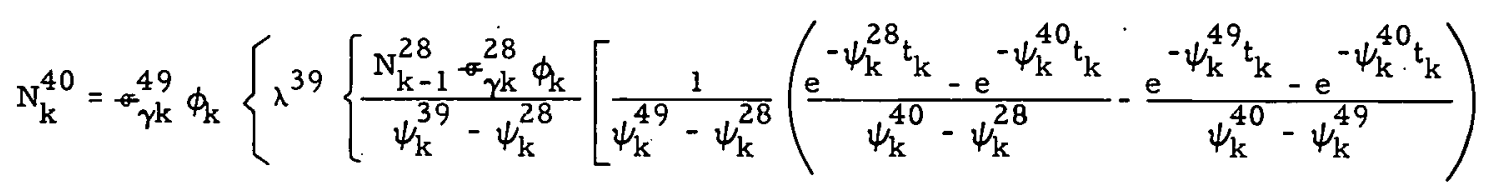

$$
\begin{aligned}
& \left.-\frac{1}{\psi_{k}^{49}-\psi_{k}^{39}}\left(\frac{e^{-\psi_{k}^{39} t_{k}}-e^{-\psi_{k}^{40} t_{k}}}{\psi_{k}^{40}-\psi_{k}^{39}}-\frac{e^{-\psi_{k}^{49} t_{k}}-e^{-\psi_{k}^{40} t_{k}}}{\psi_{k}^{40}-\psi_{k}^{49}}\right)\right] \\
& \left.+\frac{\mathrm{N}_{\mathrm{k}-1}^{39}}{\psi_{\mathrm{k}}^{49}-\psi_{\mathrm{k}}^{39}}\left[\frac{\mathrm{e}^{-\psi_{\mathrm{k}}^{39} \mathrm{t}_{\mathrm{k}}-\mathrm{e}^{-\psi_{\mathrm{k}}^{40} \mathrm{t}}}}{\psi_{\mathrm{k}}^{40}-\psi_{\mathrm{k}}^{39}}-\frac{\mathrm{e}^{-\psi_{\mathrm{k}}^{49} \mathrm{t}_{\mathrm{k}}}-\mathrm{e}^{-\psi_{\mathrm{k}}^{40} \mathrm{t}}}{\psi_{\mathrm{k}}^{40}-\psi_{\mathrm{k}}^{49}}\right]\right\} \\
& \left.+\frac{\mathrm{N}_{\mathrm{k}-1}^{49}}{\psi_{\mathrm{k}}^{40}-\psi_{\mathrm{k}}^{49}}\left[\mathrm{e}^{-\psi_{\mathrm{k}}^{49} \mathrm{t}}-\mathrm{e}^{-\psi_{\mathrm{k}}^{40} \mathrm{t}_{\mathrm{k}}}\right]\right\}+\mathrm{N}_{\mathrm{k}-1}^{40} \mathrm{e}^{-\psi_{\mathrm{k}}^{40} \mathrm{t}_{\mathrm{k}}}
\end{aligned}
$$

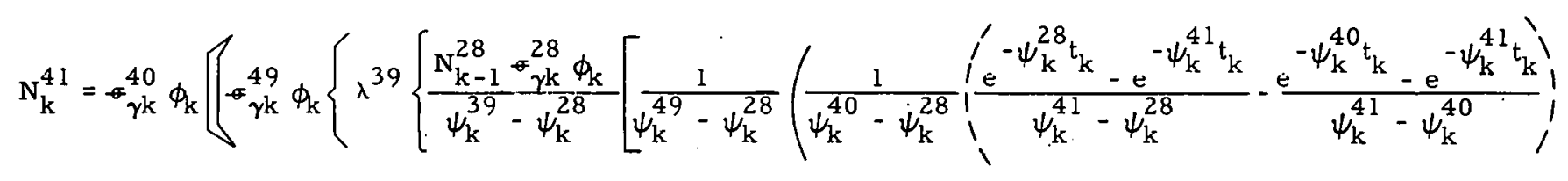

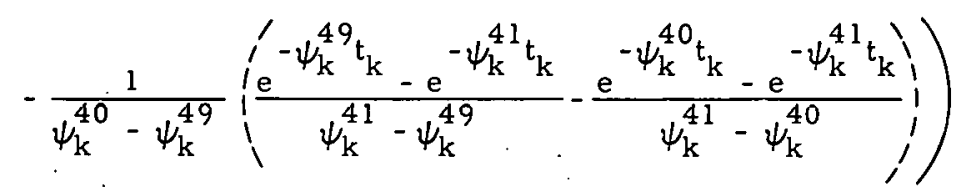

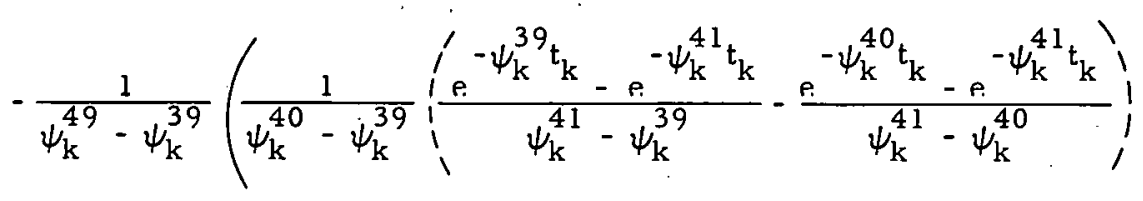

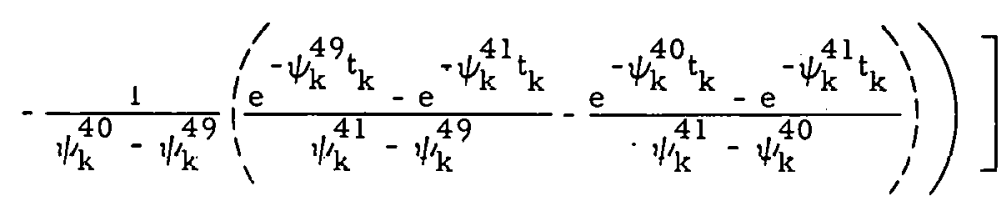




$$
\begin{aligned}
& +\frac{N_{k-1}^{39}}{\psi_{k}^{49}-\psi_{k}^{39}}\left[\frac{1}{\psi_{k}^{40}-\psi_{k}^{39}}\left(\frac{e^{-\psi_{k}^{39} t_{k}}-e^{-\psi_{k}^{41} t_{k}}}{\psi_{k}^{41}-\psi_{k}^{39}}-\frac{e^{-\psi_{k}^{40} t_{k}}-e^{-\psi_{k}^{41} t_{k}}}{\psi_{k}^{41}-\psi_{k}^{40}}\right)\right. \\
& \left.\left.-\frac{1}{\psi_{k}^{40}-\dot{\psi}_{k}^{49}}\left(\frac{e^{-\psi_{k}^{49} t_{k}}-e^{-\psi_{k}^{41} t_{k}}}{\psi_{k}^{41}-\psi_{k}^{49}}-\frac{e^{-\psi_{k}^{40} t_{k}}-e^{-\psi_{k}^{41} t_{k}}}{\psi_{k}^{41}-\psi_{k}^{40}}\right)\right]\right\} \\
& \left.+\frac{N_{k}^{49}}{\psi_{k}^{40}-\psi_{k}^{49}}\left[\frac{e^{-\psi_{k}^{49} t_{k}}-e^{-\psi_{k}^{41} t_{k}}}{\psi_{k}^{41}-\psi_{k}^{49}}-\frac{e^{-\psi_{k}^{40} t_{k}}-e^{-\psi_{k}^{41} t_{k}}}{\psi_{k}^{41}-\psi_{k}^{40}}\right]\right\} \\
& \left.+\frac{N_{k-1}^{40}}{\psi_{k}^{41}-\psi_{k}^{40}}\left[e^{-\psi_{k}^{40} t_{k}}-e^{-\psi_{k}^{41} t_{k}}\right]\right]+N_{k-1}^{41} e^{-\psi_{k}^{41} t_{k}}
\end{aligned}
$$

Number of Fissions in Each Fissionable Isotope during $k^{\text {th }}$ Irradiation Step

$$
\begin{aligned}
& F_{k}^{25}=\left(N_{k-1}^{25}-N_{k}^{25}\right)\left(-\sigma_{a k}^{25}-\sigma_{\gamma k}^{25}\right) \phi_{k} / \psi_{k}^{25} \\
& \mathrm{~F}_{\mathrm{k}}^{28}=\left(\mathrm{N}_{\mathrm{k}-1}^{28}-\mathrm{N}_{\mathrm{k}}^{28}\right)\left(\boldsymbol{\sigma}_{\mathrm{ak}}^{28}-{ }_{\gamma \mathrm{k}}^{28}\right) \phi_{\mathrm{k}} / \psi_{\mathrm{k}}^{28} \\
& F_{k}^{49}=\left(\sigma_{a k}^{49}-\sigma_{\gamma k}^{49}\right) \phi_{k}\left\{\lambda ^ { 3 9 } \left\{\frac { N _ { k - 1 } ^ { 2 8 } \sigma _ { \gamma k } ^ { 2 8 } \phi _ { k } } { \psi _ { k } ^ { 3 9 } - \psi _ { k } ^ { 2 8 } } \left[\frac{1}{\psi_{k}^{49}-\psi_{k}^{28}}\left(\frac{1-e^{-\psi_{k}^{28} t_{k}}}{\psi_{k}^{28}}-\frac{1-e^{-\psi_{k}^{49} t_{k}}}{\psi_{k}^{49}}\right)\right.\right.\right. \\
& \left.-\frac{1}{\psi_{k}^{49}-\psi_{1 \mathrm{~g}}^{39}}\left(\frac{1 \cdot \mathrm{c}^{-1 / \mathrm{k}_{\mathrm{k}}^{39} \mathrm{t}_{\mathrm{k}}}}{\psi_{\mathrm{k}}^{39}}-\frac{1 \cdot \mathrm{c}^{-1 / 4 \mathrm{k}^{49} \mathrm{t}}}{\psi_{\mathrm{k}}^{49}}\right)\right] \\
& \left.\left.+\frac{N_{k-1}^{39}}{\psi_{k}^{49}-\psi_{k}^{39}}\left(\frac{1-e^{-\psi_{k}^{39} t_{k}}}{\psi_{k}^{39}}-\frac{1-e^{-\psi_{k}^{49} t_{k}}}{\psi_{k}^{49}}\right)\right\}+\frac{N_{k-1}^{49}}{\psi_{k}^{49}}\left(1-e^{-\psi_{k}^{49} t_{k}}\right)\right\} \\
& F_{k}^{41}=\left(\sigma_{a k}^{41}-\sigma_{\gamma k}^{41}\right) \phi_{k}\left\{\left\{\sigma _ { \gamma k } ^ { 4 0 } \phi _ { k } \left[\left(\sigma _ { \gamma k } ^ { 4 9 } \phi _ { k } \left\{\lambda ^ { 3 9 } \left\{\frac { N _ { k - 1 } ^ { 2 8 } \gamma _ { k } ^ { 2 8 } \phi _ { k } } { \psi _ { k } ^ { 3 9 } - \psi _ { k } ^ { 2 8 } } \left\{\frac { 1 } { \psi _ { k } ^ { 4 9 } - \psi _ { k } ^ { 2 8 } } \left[\frac { 1 } { \psi _ { k } ^ { 1 0 } - \psi _ { k } ^ { 2 8 } } \left(\frac{1}{\psi_{k}^{11}-\psi_{k}^{28}} ! \frac{1-e^{-\psi_{k}^{28} t_{k}}}{\psi_{k}^{28}}\right.\right.\right.\right.\right.\right.\right.\right.\right. \\
& \left.-\frac{1-\mathrm{e}^{-\psi_{\mathrm{k}}^{41} \mathrm{t}_{\mathrm{k}}}}{\psi_{\mathrm{k}}^{41}}\right)-\frac{1}{\psi_{\mathrm{k}}^{41}-\psi_{\mathrm{k}}^{40}}\left(\frac{1-\mathrm{e}^{-\psi_{\mathrm{k}}^{40} \mathrm{t}_{\mathrm{k}}}}{\psi_{\mathrm{k}}^{40}}-\frac{1-\mathrm{e}^{-\psi_{\mathrm{k}}^{41} \mathrm{t}_{\mathrm{k}}}}{\psi_{\mathrm{k}}^{41}}\right)
\end{aligned}
$$




$$
\begin{aligned}
& -\frac{1}{\psi_{\mathrm{k}}^{40}-\psi_{\mathrm{k}}^{49}}\left(\frac{1}{\psi_{\mathrm{k}}^{41}-\psi_{\mathrm{k}}^{49}} \frac{1-\mathrm{e}^{-\psi_{\mathrm{k}}^{49} \mathrm{t}_{\mathrm{k}}}}{\psi_{\mathrm{k}}^{49}}-\frac{1-\mathrm{e}^{-\psi_{\mathrm{k}}^{41} \mathrm{t}_{\mathrm{k}}}}{\psi_{\mathrm{k}}^{41}}\right) \\
& \left.-\frac{1}{\psi_{\mathrm{k}}^{41}-\psi_{\mathrm{k}}^{40}}\left(\frac{1-\mathrm{e}^{-\psi_{\mathrm{k}}^{40} \mathrm{t}_{\mathrm{k}}}}{\psi_{\mathrm{k}}^{40}}-\frac{1-\mathrm{e}^{-\psi_{\mathrm{k}}^{41} \mathrm{t}_{\mathrm{k}}}}{\psi_{\mathrm{k}}^{41}} \vdots\right)\right] \\
& -\frac{1}{\psi_{\mathrm{k}}^{49}-\psi_{\mathrm{k}}^{39}}\left[\frac { 1 } { \psi _ { \mathrm { k } } ^ { 4 0 } - \psi _ { \mathrm { k } } ^ { 3 9 } } \left(\frac{1}{\psi_{\mathrm{k}}^{41}-\psi_{\mathrm{k}}^{39}}\left(\frac{1-\mathrm{e}^{-\psi_{\mathrm{k}}^{39} \mathrm{k}}}{\psi_{\mathrm{k}}^{39}}-\frac{1-\mathrm{e}^{-\psi_{\mathrm{k}}^{41}} \mathrm{k}}{\psi_{\mathrm{k}}^{41}}\right)\right.\right. \\
& -\frac{1}{\psi_{\mathrm{k}}^{41}-\psi_{\mathrm{k}}^{40}}\left(\frac{1-\mathrm{e}^{-\psi_{\mathrm{k}}^{40} \mathrm{t}}}{\psi_{\mathrm{k}}^{40}}-\frac{1-\mathrm{e}^{-\psi_{\mathrm{k}}^{41} \mathrm{t}_{\mathrm{k}}}}{\psi_{\mathrm{k}}^{41}}\right) \\
& \left.-\frac{1}{\psi_{\mathrm{k}}^{40}-\psi_{\mathrm{k}}^{49}}\left(\frac{1}{\psi_{\mathrm{k}}^{41}-\psi_{\mathrm{k}}^{49}}\right)^{\prime} \frac{1-\mathrm{e}^{-\psi_{\mathrm{k}}^{49} \mathrm{t}_{\mathrm{k}}}}{\psi_{\mathrm{k}}^{49}}-\frac{1-\mathrm{e}^{-\psi_{\mathrm{k}}^{41} \mathrm{t}_{\mathrm{k}}}}{\psi_{\mathrm{k}}^{41}}\right) \\
& \left.-\frac{1}{\psi_{\mathrm{k}}^{41}-\psi_{\mathrm{k}}^{40}}\left(\frac{1-\mathrm{e}^{-\psi_{\mathrm{k}}^{40} \mathrm{k}}}{\psi_{\mathrm{k}}^{40}}-\frac{1-\mathrm{e}^{-\psi_{\mathrm{k}}^{41} \mathrm{t}_{\mathrm{k}}}}{\psi_{\mathrm{k}}^{41}}\right)\right] \\
& +\frac{\mathrm{N}_{\mathrm{k}-1}^{39}}{\psi_{\mathrm{k}}^{49}-\psi_{\mathrm{k}}^{39}}\left\{\frac { 1 } { \psi _ { \mathrm { k } } ^ { 4 0 } - \psi _ { \mathrm { k } } ^ { 3 9 } } \left[\frac{1}{\psi_{\mathrm{k}}^{41}-\psi_{\mathrm{k}}^{39}}\left(\frac{1-\mathrm{e}^{-\psi_{\mathrm{k}}^{39} \mathrm{t}_{\mathrm{k}}}}{\psi_{\mathrm{k}}^{39}}-\frac{1-\mathrm{e}^{-\psi_{\mathrm{k}}^{41} \mathrm{t}}}{\psi_{\mathrm{k}}^{41}}\right)\right.\right. \\
& \left.-\frac{1}{\psi_{k}^{41}-\psi_{k}^{40}}\left(\frac{1-e^{-\psi_{k}^{40} t_{k}}}{\psi_{k}^{40}}-\frac{1-e^{-\psi_{k}^{41} t_{k}}}{\psi_{k}^{41}}\right)\right] \\
& \left.-\frac{1}{\psi_{k}^{40}-\psi_{k}^{19}}\left[\frac{1}{\psi_{k}^{41}-\psi_{k}^{49}}\left(\frac{1-e^{-\psi_{k}^{49} t_{k}}}{\psi_{k}^{49}}-\frac{1-e^{-\psi_{k}^{41} t_{k}}}{\psi_{k}^{41}}\right)-\frac{1}{\psi_{k}^{41}-\psi_{k}^{40}}\left(\frac{1-e^{-\psi_{k}^{40} t_{k}}}{\psi_{k}^{40}}-\frac{1-c^{-\psi_{k}^{41} t_{k}}}{\psi_{k}^{41}}\right)\right]\right\} \\
& \left.+\frac{N_{k}^{49}}{\psi_{k}^{40}-\psi_{k}^{49}}\left[\frac{1}{\psi_{k}^{11}-\psi_{k}^{49}}\left(\frac{1-e^{-\psi_{k}^{49} t_{k}}}{\psi_{k}^{49}}-\frac{1-e^{-\psi_{k}^{41} t_{k}}}{\psi_{k}^{41}}\right)-\frac{1}{\psi_{k}^{41}-\psi_{k}^{40}}\left(\frac{1-e^{-\psi_{k}^{40} t_{k}}}{\psi_{k}^{40}}-\frac{1-e^{-\psi_{k}^{41} t_{k}}}{\psi_{k}^{41}}\right)\right]\right\} \\
& \left.\left.\left.+\frac{N_{k-1}^{40}}{\psi_{k}^{41}-\psi_{k}^{40}}\left(\frac{1-e^{-\psi_{k}^{40} t_{k}}}{\psi_{k}^{40}}-\frac{1-e^{-\psi_{k}^{41} t_{k}}}{\psi_{k}^{41}}\right)\right)+N_{k-1}^{41}\left(\frac{1-e^{-\psi_{k}^{41} t_{k}}}{w_{k}^{41}}\right)\right\}\right\}
\end{aligned}
$$


In the following, the summations over $u, v$ pertain to U-235, U-238, Pu-239, and Pu-241; I, Xe, $\mathrm{Nd}, \mathrm{Pm}$, and Sm refer to I-135, Xe-135, Nd-149, Pm-149, and Sm-149.

$$
\begin{aligned}
& N_{k}^{I}=\frac{1-e^{-\psi_{k}^{I} t_{k}}}{\psi_{k}^{I}} \sum_{u, v} y_{I}^{u, v} F_{k}^{u, v} \cdot t_{k}+N_{k-1}^{I} e^{-\psi_{k}^{I} t_{k}} \\
& N_{k}^{X e}=\frac{1-e^{-\psi_{k}^{X e} t_{k}}}{\psi_{k}^{X e}} \sum_{u, v} \frac{F_{k}^{u, v}}{t_{k}}\left(y_{X e}^{u, v}+y_{I}^{u, v} \lambda^{I} / \psi_{k}^{I}\right) \\
& +\lambda^{I} \frac{e^{-\psi_{k}^{I} t_{k}}-e^{-\psi_{k}^{X e} t_{k}}}{\psi_{k}^{X e}-\psi_{k}^{I}}\left(N_{k-1}^{I}-\frac{1}{\psi_{k}^{I}} \sum_{u, v} y_{I}^{u, v} \frac{F_{k}^{u, v}}{t_{k}}\right)+N_{k-1}^{X e} e^{-\psi_{k}^{X e} t_{k}}
\end{aligned}
$$

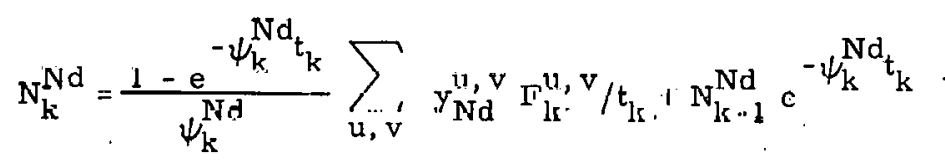

$$
\begin{aligned}
& N_{k}^{P m}=\frac{1-e^{-\psi_{k}^{P m_{t}}}}{\psi_{k}^{P m}} \sum_{u, v} \frac{F_{k}^{u, v}}{t_{k}}\left(y_{P m}^{u, v}+y_{N d}^{u, v} \lambda^{N d} / \psi_{k}^{N d}\right) \\
& +\lambda^{N d} \frac{e^{-\psi_{k}^{N d} t_{k}}-e^{-\psi_{k}^{P m_{t_{k}}}}}{\psi_{k}^{P m}-\psi_{k}^{N d}}\left({ }_{N}^{N d}-\frac{1}{\psi_{k}^{N d}} \sum_{u, v} y_{N d}^{u, v} \frac{F_{k}^{u, v}}{t_{k s}}\right) \\
& +N_{k-1}^{P m} e^{-\psi_{k s}^{P m_{t}}} \\
& N_{k}^{S m}=\frac{1-e^{-\psi_{k}^{S m}} \psi_{k}^{S m}}{\psi_{k}^{S m}} \sum_{u, v} y_{S m}^{u, v} F_{k}^{u, v} / t_{k}
\end{aligned}
$$

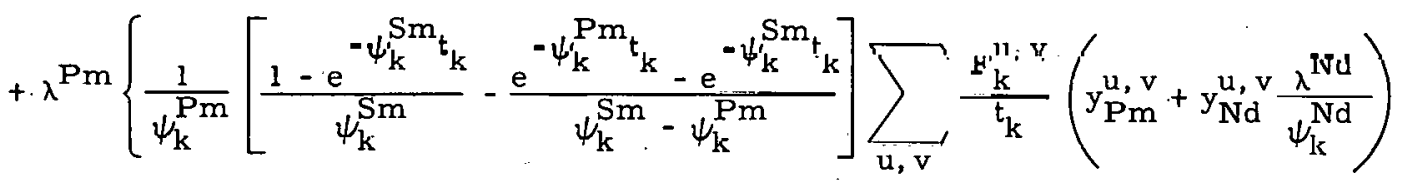

$$
\begin{aligned}
& +\lambda^{N d}\left(N_{k-1}^{N d}-\frac{1}{\psi_{k}^{N d}} \sum_{n, v} y_{N d}^{u, v} \frac{F_{k}^{u, v}}{t_{k}}\right) \frac{1}{\psi_{k}^{P m}-\psi_{k}^{N d}}\left[\frac{e^{-\psi_{k}^{N d} t_{k}}-e^{-\psi_{k}^{S m_{t}}} \psi_{k}^{S m}-\psi_{k}^{N d}}{\psi^{S d}} \frac{e^{-\psi_{k}^{P m_{t}}}-e^{-\psi_{k}^{S m} t_{k}}}{\psi_{k}^{S m}-\psi_{k}^{P m}}\right] \\
& \left.+N_{k-1}^{P m} \frac{e^{-\psi_{k}^{P m_{t_{k}}}-e^{-\psi_{k}^{S m} t_{k}}}}{\psi_{k}^{S m}-\psi_{k}^{P m}}\right\}+N_{k-1}^{S m} e^{-\psi_{k}^{S m} t_{k}}
\end{aligned}
$$


For the special case of zero flux, expressions (A1) through (A18) reduce to the following:

$$
\begin{aligned}
& \mathrm{N}_{\mathrm{k}}^{25}=\mathrm{N}_{\mathrm{k}-1}^{25} \\
& \mathrm{~N}_{\mathrm{k}}^{25}=\mathrm{N}_{\mathrm{k}-1}^{26} \\
& N_{k}^{27}=N_{k-1}^{27} e^{-\lambda^{27} t_{k}} \\
& \mathrm{~N}_{k}^{37}=\mathrm{N}_{\mathrm{k}-1}^{37}+\mathrm{N}_{\mathrm{k}-1}^{27}\left(1-\mathrm{e}^{-\lambda^{27} \mathrm{t}_{\mathrm{k}}}\right) \\
& \mathrm{N}_{\mathrm{k}}^{28}=\mathrm{N}_{\mathrm{k}-1}^{28} \\
& N_{k}^{39}=N_{k-1}^{39} e^{-\lambda^{39} t_{k}} \\
& N_{k}^{49}=N_{k-1}^{49}+N_{k-1}^{39}\left(1-e^{-\lambda^{39} t_{k}}\right) \\
& \mathrm{N}_{\mathrm{k}}^{40}=\mathrm{N}_{\mathrm{k}-1}^{40} \\
& N_{k}^{41}=N_{k-1}^{41} e^{-\lambda^{41} t_{k}} \\
& \mathrm{~F}_{\mathrm{k}}^{25}=0 \\
& \mathrm{~F}_{\mathrm{k}}^{28}=0 \\
& \mathrm{~F}_{\mathrm{k}}^{49}=0 \\
& F_{k}^{41}=0 \\
& N_{k}^{I}=N_{k-1}^{I} e^{-\lambda^{I} t_{k}} \\
& N_{k}^{X e}=\lambda^{\top} \frac{e^{-\lambda^{I} t_{k}}-e^{-\lambda^{X e} t_{k}}}{\lambda^{X e}-\lambda^{I}} N_{k-1}^{I}+N_{k-1}^{X c} e^{-\lambda^{X e} t_{k}} \\
& N_{k}^{N d}=N_{k-1}^{N d} e^{-\lambda^{N d_{t_{k}}}}
\end{aligned}
$$




$$
\begin{gathered}
N_{k}^{P m}=\lambda^{N d} \frac{e^{-\lambda^{N d} t_{k}}-e^{-\lambda^{P m_{t_{k}}}}}{\lambda^{P m}-\lambda^{N d}} N_{i}^{N d}+N_{k-1}^{N m} e^{-\lambda^{P m_{t}}} \\
N_{k}^{S m}=\frac{\lambda^{P m}\left(1-e^{-\lambda^{N d_{t}}}\right)-\lambda^{N d}\left(1-e^{-\lambda^{P m_{t}}}\right)}{\lambda^{P m}-\lambda^{N d}} N_{k-1}^{N d}+N_{k-1}^{P m}\left(1-e^{-\lambda^{P m_{t_{k}}}}\right)+N_{k-1}^{S m}
\end{gathered}
$$

Expressions for Energy Density in MWD/T

By definition,

$\sum_{i, j} A^{i, j} N_{o}^{i, j}=235 N_{o}^{25}+236 N_{o}^{26}+237 N_{o}^{27}+237 N_{o}^{37}+238 N_{o}^{28}+239 N_{o}^{39}+239 N_{o}^{49}+240 N_{o}^{40}+241 N_{o}^{41}$, where the subscript o refers to the initial or pre-irradiation situation. Symbolically, let

Isotopic energy density $=E^{i, j} / m$ for the energy per unit mass (of fuel initially present) in the fission of lsotope $i, j$.

Energy per fission $=Q^{i, j}$ for the fission of isotope $i, j$ in units of Mev.

Then, the isotopic energy densities for the $k^{\text {th }}$ irradiation step may be written

$$
\begin{aligned}
& E_{k}^{25} / m=\frac{F_{k}^{25} Q^{25}}{\sum_{i, j} A^{i, j} N_{o}^{i, j}}\left(1.0140 \times 10^{6}\right) \text { in } M W D / T \\
& E_{k}^{28} / m=\frac{F_{k}^{28} Q^{28}}{\sum_{1, j} A^{i, j} N_{o}^{i, j}}\left(1.0140 \times 10^{6}\right) \text { in } M W D / T \\
& E_{k}^{19} / m=\frac{F_{k}^{49} Q^{49}}{\sum_{i, j}^{1} A^{1, j} N_{o}^{1, j}}\left(1.0140 \times 10^{6}\right) \text { in } M W L / T \\
& F_{k}^{41 / m}=\frac{F_{k}^{41} Q^{41}}{\sum_{i, j} A^{i, j} N_{o}^{i, j}}\left(1, n 14 n \times 10^{6}\right) \text { in } M W D / T
\end{aligned}
$$

The total energy density from all isotopes during the $k^{\text {th }}$. step is

$$
E_{k} / m=\frac{\sum_{1, j} F_{k}^{i, j} Q^{i, j}}{\sum_{i, j} A^{i, j} N_{o}^{i, j}} \cdot\left(1.0140 \times 10^{6}\right) \text { in } M W D / T \text {, }
$$

which is the sum of (A37) through (A40). The summations of each of the expressions (A37) through (A41) over all $\mathrm{k}$ irradiation steps would give the accumulated isotopic and total energy densities. Expressions for the Conversion Ratios

The thermal, epithermal, and total conversion ratios may be written, respectively, as follows: 


$$
\begin{aligned}
& (\mathrm{CR})_{\mathrm{th}}=\frac{\mathrm{N}_{\mathrm{k}}^{28} \cdot \bar{\sigma}_{\gamma \mathrm{k}}^{28}+\mathrm{N}_{\mathrm{k}}^{40} \bar{\sigma}_{\gamma \mathrm{k}}^{40}}{\mathrm{~N}_{\mathrm{k}}^{25} \sigma_{\mathrm{ak}}^{25}+\mathrm{N}_{\mathrm{k}}^{49}{ }_{\mathrm{ak}}^{49}+\mathrm{N}_{\mathrm{k}}^{41}+1} \\
& (C R)_{f}^{\prime \prime}=\frac{N_{k}^{28} R_{\gamma k}^{28}+N_{k}^{40} R_{\gamma k}^{40}}{N_{k}^{25} \sigma_{a k}^{25}+N_{k}^{49}-\sigma_{a k}^{49}+N_{k}^{41} \sigma_{a k}^{41}}\left(\phi_{R} / \phi\right)_{k} \\
& C R=\frac{N_{k}^{28} \sigma^{28}+N_{k}^{40} \sigma_{\gamma k}^{40}}{N_{k}^{25} \sigma_{a k}^{25}+N_{k}^{49} \sigma_{a k}^{49}+N_{k}^{41} \sigma_{a k}^{41}}
\end{aligned}
$$

: which is equal to the sum of (A42) and (A43).

Expressions for the Regeneration Factor $\eta$ and the Product $\eta f$

The regeneration factor $\eta$ or the number of neutrons produced per neutron absorbed in fuel material is defined by

$$
\eta_{k}=\sum_{u, v} \nu^{u, v}\left(\bar{\sigma}_{a k}^{u, v}-\bar{\sigma}_{\gamma k}^{u, v}\right) N_{k}^{u, v} / \sum_{i, j} \bar{\sigma}_{a k}^{i, j} N_{k}^{i, j}
$$

where $\nu^{\mathrm{u}, \mathrm{v}}$ is the average number of fission neutrons produced per thermal fission of isotope $u, v$; $\bar{\sigma}_{\mathrm{ak}}^{\mathrm{u}, \mathrm{v}}$ and $\bar{\sigma}_{\boldsymbol{\gamma} \mathrm{k}}^{\mathrm{u}} \mathrm{v}$ are effective thermal cross sections for absorption and capture; and the summations extend over all fissionable isotopes $u, v$ and all absorbing isotopes $i, j$ within the fuel volume. A term for fission-product poisons which may be written as a double summation over the $\mathrm{k}$ irradiation steps and the $u, v$ fissionable isotopes is included implicitly in the denominator:

$$
\sum_{\mathrm{k}} \sum_{\mathrm{u}, \mathrm{v}} \bar{\sigma}_{\mathrm{FP}, \mathrm{k}}^{\mathrm{u}, \mathrm{v}} \mathrm{F}_{\mathrm{k}}^{\mathrm{u}, \mathrm{v}}
$$

where $\bar{\sigma}_{\mathrm{FP}, \mathrm{k}}^{\mathrm{u}, \mathrm{v}}$ is the effective thermal absorption cross section per fission for fission products from the fission of isotope $u, v$--the so-called "barn per fission" quantity for each fissionable isotope. Since this quantity may vary with irradiation, the subscript $\mathrm{k}$ is included.

Expression (A45) is also used for the product $\eta f$, if the summation in the denominator is interpreted to include terms for absorption in the moderator and structural materials.

If $\eta_{0}$ and $(\eta f)_{0}$ pertain to the situation prior to irradiation, expression (A45) may be used to evaluate

$$
\frac{\Delta \eta}{\eta_{0}}=\frac{\eta_{\mathrm{k}}-\eta_{\mathrm{o}}}{\eta_{\mathrm{o}}}
$$

and

$$
\frac{\Delta(\eta f)}{(\eta f)_{0}}=\frac{(\eta f)_{k}-(\eta f)_{0}}{(\eta f)_{0}} .
$$


DETAILS OF THE S0269 CODE

Input Quantities and Their Locations in the Code

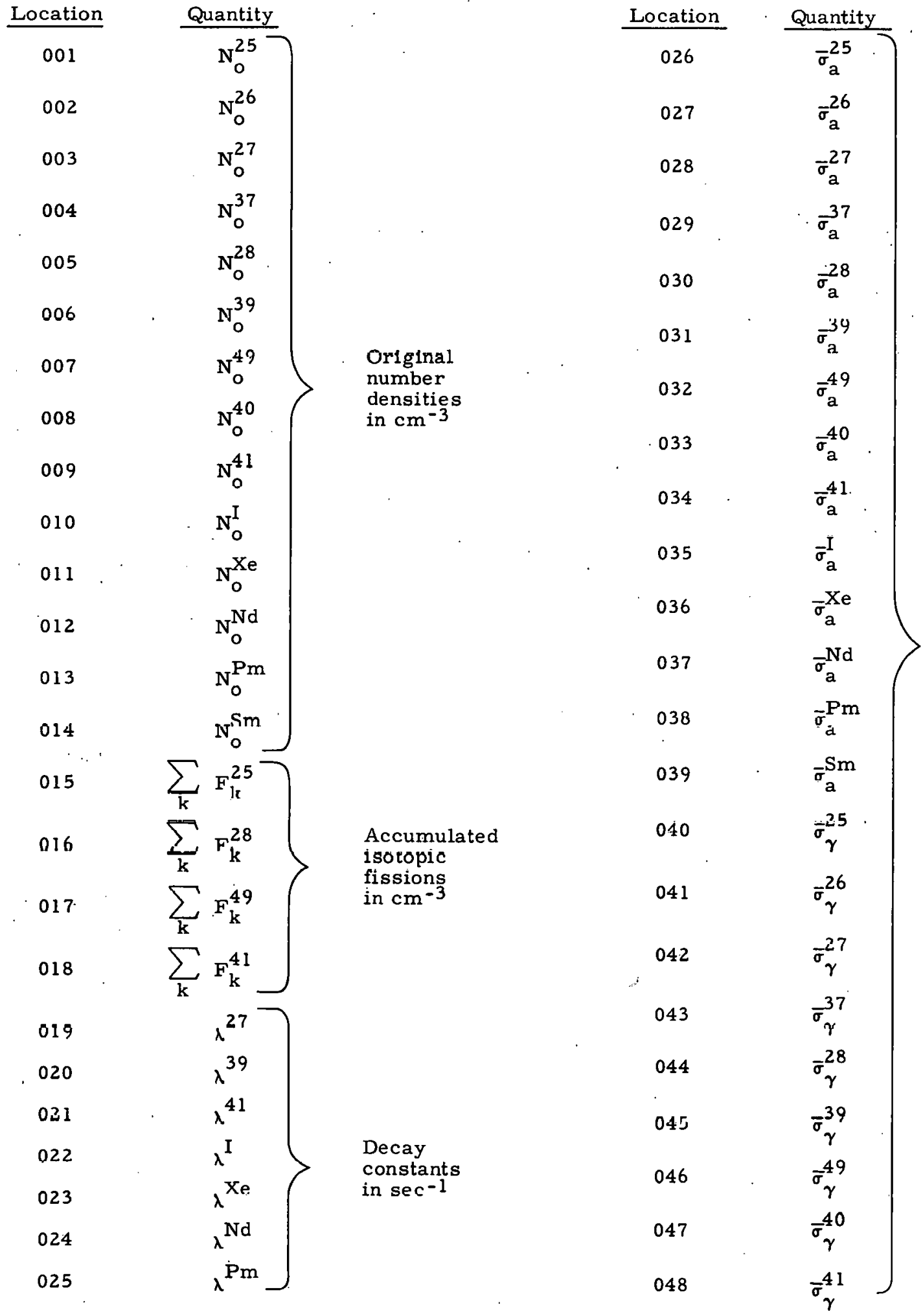

Effective thermal cross sections in $\mathrm{cm}^{2}$ 


\begin{tabular}{|c|c|c|c|c|c|}
\hline Location & Quantity & & Location & Quantity & \\
\hline 049 & $\mathrm{R}_{\mathrm{a}}^{25}$ & & 073 & $Q^{25}$ & \\
\hline 050 & $\mathrm{R}_{\mathrm{a}}^{26}$ & $\therefore$ & 074 & $Q^{28}$ & $\begin{array}{l}\text { Energy per } \\
\text { fission in }\end{array}$ \\
\hline 051 & $\mathrm{R}_{\mathrm{a}}^{27}$ & $\therefore .$. & 075 & $Q^{49}$ & Mev \\
\hline 052 & $\mathrm{R}_{\mathrm{a}}^{37}$ & & 076 & $Q^{41}$ & \\
\hline 053 & $\mathrm{R}_{\mathrm{a}}^{28}$ & & 077 & $\mathrm{y}_{\mathrm{I}}^{25}$ & ' \\
\hline 054 & $\mathrm{R}_{\mathrm{a}}^{39}$ & & 078 & $\mathrm{y}_{\mathrm{I}}^{28}$ & \\
\hline 055 & $\mathrm{R}_{\mathrm{a}}^{49}$ & & 079 & $y_{I}^{49}$ & \\
\hline 056 & $\mathrm{R}_{\mathrm{a}}^{40}$ & & 080 & $y_{I}^{41}$ & \\
\hline 0.57 & $\mathrm{R}_{\mathrm{a}}^{41}$ & & 081 & $\mathrm{y}_{\mathrm{Xe}}^{25}$ & $\because$ \\
\hline 058 & $\mathrm{R}_{\mathrm{a}}^{\mathrm{I}}$ & & 082 & $\mathrm{y}_{\mathrm{Xe}}^{28}$ & $\begin{array}{l}\because: \\
\because:\end{array}$ \\
\hline 059 & $\mathrm{R}_{\mathrm{a}}^{\mathrm{Xe}}$ & Epithermal & 083 & $\mathrm{y}_{\mathrm{Xe}}^{49}$ & $\cdot$ \\
\hline 060 & $\mathrm{R}_{\mathrm{a}}^{\mathrm{Nd}}$ & resonance & 084 & $y_{X e}^{41}$ & \\
\hline 061 & $\mathrm{R}_{\mathrm{a}}^{\mathrm{Pm}}$ & in $\mathrm{cm}^{2}$ & 085 & $\mathrm{y}_{\mathrm{Nd}}^{25}$ & \\
\hline 062 & $\mathrm{R}_{\mathrm{a}}^{\mathrm{Sm}}$ & & 086 & $\mathrm{y}_{\mathrm{Nd}}^{28}$ & Isotopic fission \\
\hline 063 & $\mathrm{R}_{\gamma}^{25}$ & & 087 & $\mathrm{y}_{\mathrm{Nd}}^{49}$ & (fractional) \\
\hline 064 & $R_{\gamma}^{26}$ & & 088 & $\mathrm{y}_{\mathrm{Nd}}^{41}$ & \\
\hline 065 & $\mathrm{R}_{\gamma}^{27}$ & & 089 & $\mathrm{y}_{\mathrm{Pm}}^{25}$ & \\
\hline 066 & $\mathrm{R}_{\gamma}^{37}$ & & 090 & $\mathrm{y}_{\mathrm{Pm}}^{28}$ & \\
\hline 067 & $\mathrm{R}_{\gamma}^{28}$ & & 091 & $\mathrm{y}_{\mathrm{Pm}}^{49}$ & \\
\hline 068 & $\mathrm{R}_{\gamma}^{39}$ & & 092 & $y_{\mathrm{Pm}}^{4}$ & \\
\hline 069 & $\mathrm{R}_{\gamma}^{49}$ & & 093 & $\mathrm{y}_{\mathrm{Sm}}^{25}$ & \\
\hline 070 & $\mathbf{R}_{\gamma}^{4 \dot{\varphi}}$ & & UY4 & $\mathrm{y}_{\mathrm{Sm}}^{28}$ & \\
\hline 071 & $\mathrm{R}_{\gamma}^{41}$ & & 095 & $\mathrm{y}_{\mathrm{Sm}}^{49}$ & \\
\hline 072 & $\delta^{28}$ & $\begin{array}{l}\text { Factur for } \\
\text { fast fission }\end{array}$ & 096 & $\mathrm{y}_{\mathrm{Sm}}^{41}$ & \\
\hline
\end{tabular}




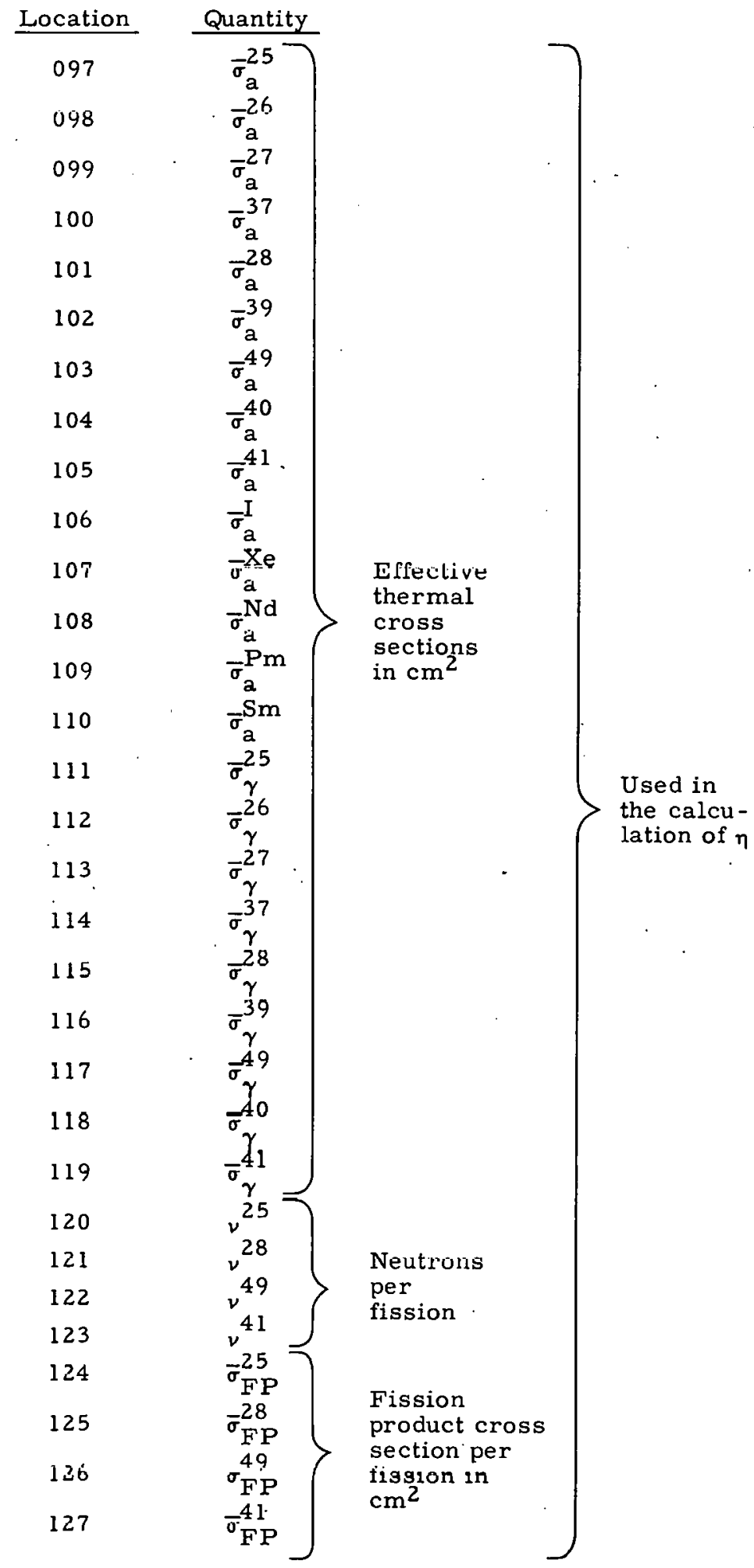

$\left.\begin{array}{ccc}\text { Location } & & \text { Quantity } \\ 128 & A^{25} \\ 129 & A^{26} \\ 130 & A^{27} \\ 131 & A^{37} \\ 132 & A^{28} \\ 133 & & A^{39} \\ 134 & & A^{49} \\ 135 & & A^{40} \\ 136 & A^{41}\end{array}\right\}$ Atomic




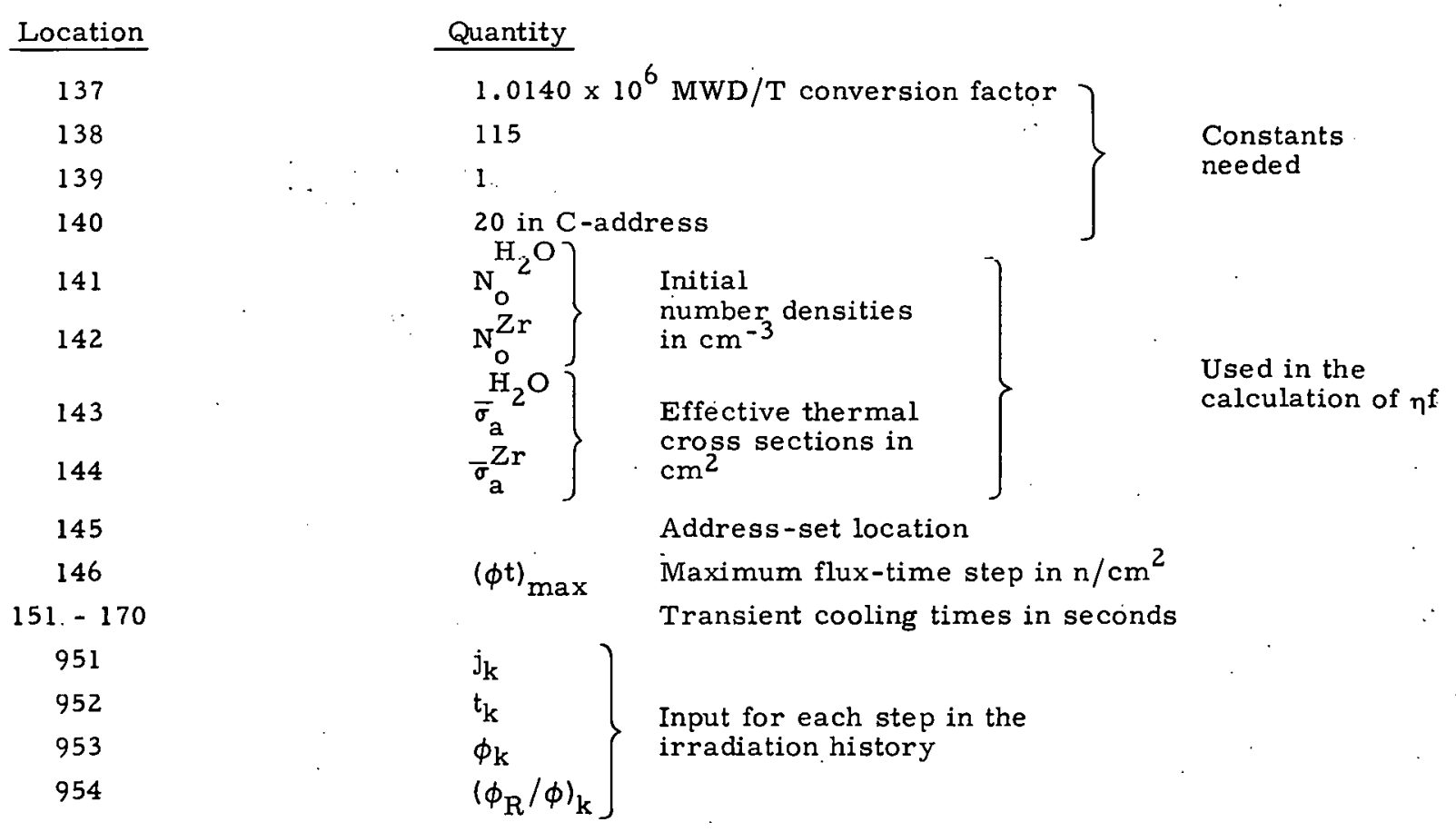

Output Quantities and Their Locations in the Code

\begin{tabular}{|c|c|c|}
\hline Location & Quantity & . \\
\hline 196 & $\sum_{k} \phi_{k} t_{k}$ & Accumulated flux-time in $\mathrm{n} / \mathrm{cm}^{2}$ \\
\hline 197 & $\mathrm{~N}_{\mathrm{k}}^{25}$ & \\
\hline 198 & $\mathrm{~N}_{\mathrm{k}}^{26}$ & \\
\hline 199 & $\mathrm{~N}_{\mathrm{k}}^{27}$ & \\
\hline 200 & $\mathrm{~N}_{\mathrm{k}}^{37}$ & \\
\hline 201 & $\mathrm{~N}_{\mathrm{k}}^{28}$ & \\
\hline 202 & $\mathrm{~N}_{\mathrm{k}}^{39}$ & Iscitopic number densities \\
\hline 203 & $\mathrm{~N}_{\mathrm{k}}^{49}$ & \\
\hline 204 & $\mathrm{~N}_{\mathrm{k}}^{40}$ & . \\
\hline 205 & $\mathrm{~N}_{\mathrm{k}}^{41}$ & \\
\hline 206 & $\mathrm{~N}_{\mathrm{k}}^{\mathrm{I}}$ & \\
\hline 207 & $\mathrm{~N}_{\mathrm{k}}^{\mathrm{Xe}}$ & \\
\hline
\end{tabular}




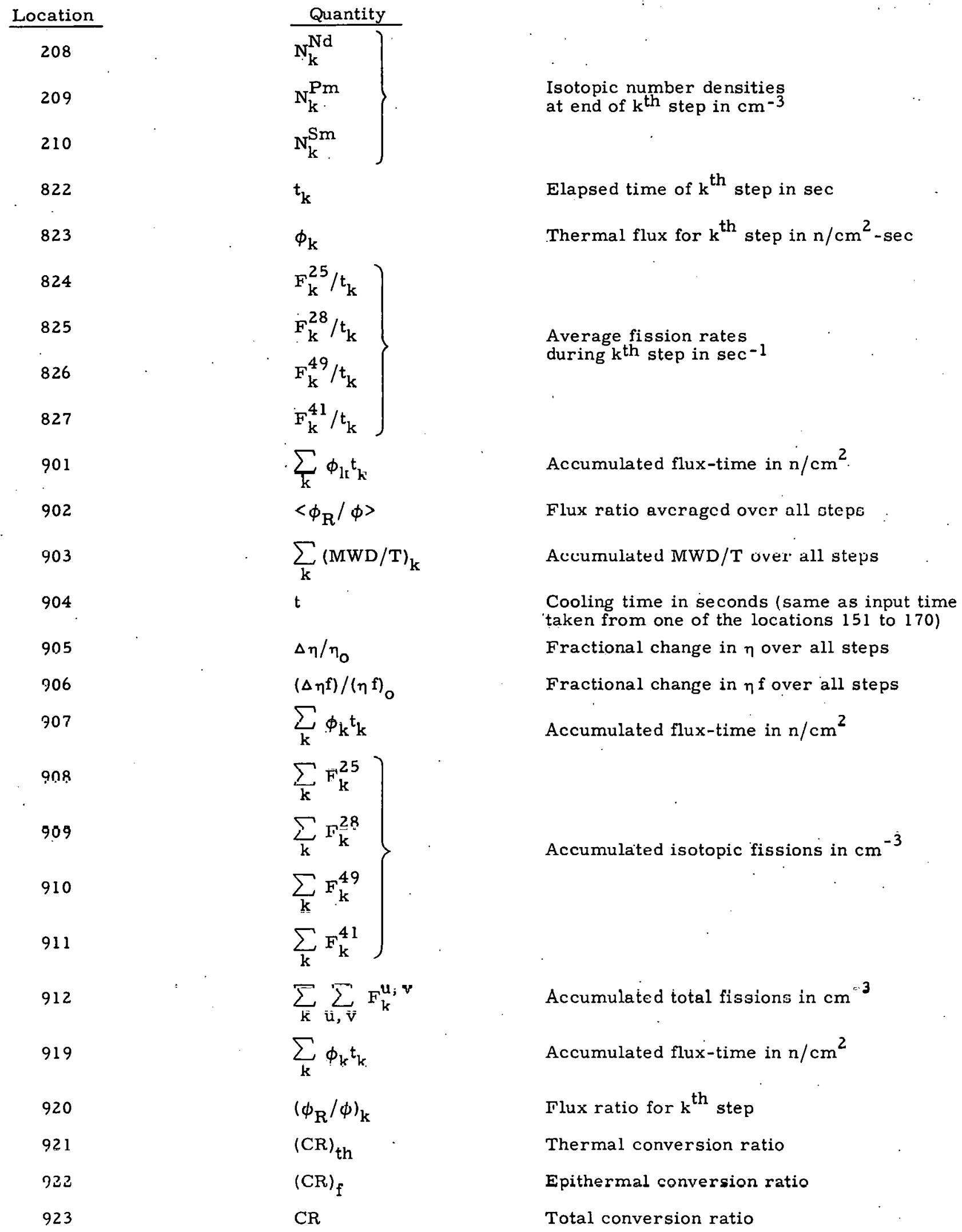




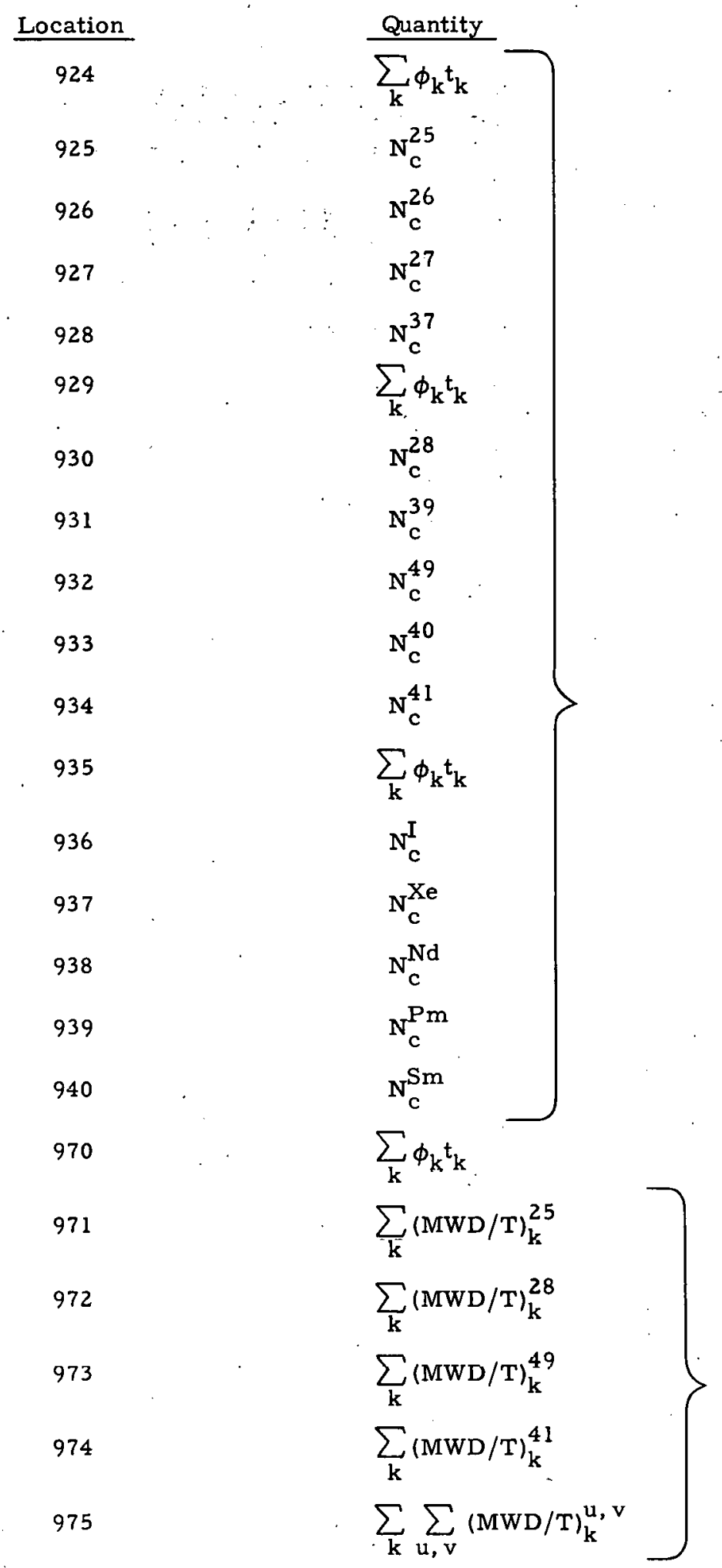

Pseudo number densities in $\mathrm{cm}^{-3}$ which would be obtained for a given cooling time. Punched on three cards, with the accumulated flux-time the first word on each card.

Accumulated flux-time in $\mathrm{n} / \mathrm{cm}^{2}$

Isotopic and total MWD/T accumulated. over all steps

Quantities in locations 700, 705, 706, and 976 are also punched for use as described in Appendix E.

\section{Code Reproduction}

The S0269 Code is reproduced on the following three pages. 
$11474+4146952900$ $21716+0410907912$ $31776+3201044722$

$41836+3000953723$

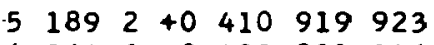
$62616+0400001146$ $\begin{array}{lllllll}7 & 267 & 6 & -3 & 128 & 001 & 691\end{array}$ $92736+0400950953$ $92796+0201280947$ $102856+2199000000$ $\begin{array}{llllll}11 & 291 & 6 & +3 & 257 & 206 \\ 112 & 298\end{array}$ $122976+3258207000$ $133036+3000024000$ $143096+2139260.000$ $153156+2139260000$ $\begin{array}{llllll}16 & 321 & 6+9 & 002 & 231 & 217\end{array}$ $\begin{array}{llllll}17327 & 6+9 & 004 & 191824\end{array}$ 18. $3336+0 \quad 090334253$ $193396+9002 \quad 197229$ $203456+2103117000$ $213516+3000237000$ $223576+0203000359$ 233636 to 202030366 $2.43696+0011004362$ $253756+1000702899$

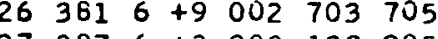
$273876+2000139905$ $283936+0 \quad 454000000$ $293996+9005233930$ 3. $4056+0.005251001$ 314116 t0 006251001 $\begin{array}{lllllll}32 & 417 & 6 & -1 & 026 & 707 & 721\end{array}$ $334236+0111009422$ $\begin{array}{llllll}34 & 4296+1 & 767 & 020 & 767\end{array}$ $\begin{array}{llllllll}35 & 435 & 6 & -0 & 301 & 776 & 790\end{array}$ $354416+2764763807$ 374476 to 101003446 $334536+2775773822$ $394596+2792793829$ $404656+2796798 \quad 838$
$+4951263195$ $+3197721721$ $+3204047000$ $+4722721921$ $+0203000941$ to 400151170 to 111009267 $+9001139263$

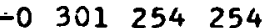
$+1000200232$ $+2257258898$ $+1000239239$ $+3000208241$ $+3000024000$ $+3000209000$ $+9002234220$ +0 203000000 $+9001151951$ $+9001201233$ $+3000122000$ $+1000701701$ $+3000097000$ $+90002520000$ +0 U50 358097 $+4701899704$ +0 410700700 $+4704706000$ $+8251000408$ +0 410924928 to 050334151 +0 203000277 +0 111014417 $\begin{array}{lllll}-2 & 721 & 744 & 753\end{array}$ $\begin{array}{lllll}-1 & 770 & 021 & 770\end{array}$ +0 006337001 $+2765763808$ $+2769768817$ $+2775774823$ $\begin{array}{lllll}-2 & 794795830\end{array}$ $+2797798839$
$+2900000000$ $+3203727000$ $+1000722722$ $+4723721922$ $+0005251001$ $\begin{array}{lll}-1 & 691 & 692692\end{array}$ $+9002951261$ +0.006 947001 +3. 255202234 $+2023022000$ $+3259208240$ $+3260209000$ +2242000242 $+1000242000$ $+9006237223$ +0.006 247001 +0 080394950 $+9001204236$ $+3000235.000$ $+9001252702$ $+1000702702$ $+0-203: 000: 367$ +u 050366124 +0 454000500 +0 410705706 $+2000139906$ +ن 005247000 +0 410929934 +0 203000326 +0 454000000 $+1725072725$ +0 111009424 +0 111006430 +0 011014432 $+2765764809$ $+2770768818$ $\begin{array}{llll}-2 & 790791824 \\ + & 011 & 004 & 460\end{array}$ +0 011004460 $+2799800840$
+0 201414913 $+1000721721$ $+3201067723$ $+1000921.923$

$+9018001197$ +0 111008269 $+8952000 \quad 147$
+0 +0 011007277 $+2202000000$ $+4898000000$ $+2259260897$ $+1000241241$ $+2025024000$ $+1000210242$ +0 008249950 +9001 140253 $+0203000277$ $+2097111000$ $+1000701701$ $-9000229229$ +0 060358001 $+3000 \cdot 124000$ $+3141143899$ $+4701702703$ +0 006248001 +9001951904 $+9001901924$ +9001901935 +0 060334001 +9001 195951 $\begin{array}{lllll}-3 & 953 & 063 & 735\end{array}$ -3 952721762

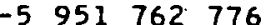
+0 005337790 $-2767766810$ $+2770769819$ to 011003455 $\begin{array}{llll}-2 & 795796834\end{array}$ $+2801802841$
$+3205729000$ $+3204070000$ $+9001901919$

+0 008328145 $+4137000700$ +0 005947254 $+1000203235$ $+3000022000$ $+2025024000$ $+2139259000$ $+4208000000$ $+8247000339$ $+8249000329$ +0 008332950 $+9000252790$ $+3000120000$ $+2105119000$ +0 202050358 +0 011014354 $+1000702702$ +3 142144000 +0 454000000 to 203000273 +0 410901906 $+9001901929$ $+9005238936$ $+9001334410$ $\begin{array}{lllll}-3 & 953 & 049 & 707\end{array}$ to 011009420 +0 011014426 $+1138000000$ $-2763762804$ +0 101004444 $+2772771820$ $+2791792827$ to 011003462 $+2801803842$
$+1000721721$ $+1000723000$ $+9001953920$

+0 008991145 $+0.203000339$ $+138000000$ $+3254199231$ $+3256205237$ $+3000206239$ $+4897000000$ $+3000025242$ $+3000242242$ $+9014197: 215$ $+9014215197$ +0 007253000 +0 203000436 $+3000123000$ $+9000252000$ $\begin{array}{llll}-9 & 000211 & 211\end{array}$ to 060366001 $+1000899000$ $+8248000386$ $+4703705000$ +0 454000000 +9004229925 +0 410935940 to 000000000 $\begin{array}{lllll}-1 & 040 & 735 & 744\end{array}$ $+1764019764$ to 201435337 +0 101003439 $\begin{array}{llll}-2 & 768 & 767814\end{array}$ $+2774773821$ $+2791793828$ $+2796797837$ $+2802803843$ 
$\begin{array}{lllllll}41 & 471 & 6 & -4 & 824 & 804 & 844\end{array}$ $424776+3952751868$ $434836+3201850886$ $444896+4201810892$ $454956+2845847000$ $465016+2846849000$ $475076+3000890218$ $485136+1000872218$ $495196+3000892000$ $505256+2855857895$ $515316+1000222000$ $525376+4000 \quad 812223$ $535436+4000815896$ $545496+3000866000$ $555556+1000223000$ $\begin{array}{llll}55 & 5556+1 & 600 & 223000 \\ 56 & 561 & 6+3 & 000 \cdot 753000\end{array}$ $575676+4000766244$

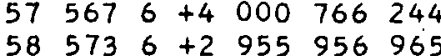
$59579.6+3000866000$ $605856+1245000000$ $615916+4969819827$ $625976+4000811246$ $636036+4000814828$ $646096+3000020246$ $656156+1000246000$ $666216+9001951261$ $676276+1000831000$ $686336+1834901901$ $696396-3 \quad 824 \quad 077 \quad 828$ $706456+1000878224$ $716516+4832771838$ $726576+3000022000$ $736636+1000830000$ $746696+1833834000$ $756756+3000.962227$ $766816+2862863000$ $776874+1000228228$ $789136+1139263263$ $799416+9001901196$ $809473+9000252254$ $819776+3228025228$ $829836+3000963000$ $83989 \cdot 6+9014215197$ 849955 t0 41.0970976 2610
+0 111020471 $+3202854887$ $+4202814893$ $+3000864000$ $+4000805218$ $+3895891000$ $+9001873219$ $+1000887000$ $+4000814000$ $+3000020000$ $+2858859000$ $+2858859000$ $+3000892223$ $+3000867000$ $+3000952000$ $\begin{array}{lllll}-2 & 139 & 794 & 954\end{array}$ $\begin{array}{llll}-2 & 954958966\end{array}$ $+3000892245$ $+3000952000$ $+2824827000$ $+2825827000$ $+2246000000$ $+2826827000$ $+3000868246$ $\begin{array}{llll}-3 & 243 & 073 & 829\end{array}$ $+1000832833$ $+3953834000$ +0111004639 $\begin{array}{lllll}-3 & 824 & 081 & 833\end{array}$ $+3000022000$ $+1000225000$ $+1000831832$ $+1000835000$ $+2208838000$ $+4000821000$ $+3209863000$ $+0.060945001$ to 410196210 +0203000281 -3 824093828 $+1000228000$ $+8950000992$ $\begin{array}{llll}+1 & 908 & 909 & 000 \\ \text { TR } & \text { CA RD } & \end{array}$
$+3952744864$ $+3203857888$ $+4203817894$ $+3000890000$ $+2848849895$ $+1000218000$ $+3886866000$ $+3000020000$ $+2222000000$ $+1000888000$ $+4000817895$ $+4000817000$ $+3896202.000$ $+1000889000$ $+4000762243$ +0 011010568 +0101004574 $+3965893000$ $+3000759245$ $+4000812246$ $+4000815828$ $+3000866000$ $+3000894000$ $+3958205000$ +0 111004622 $\begin{array}{llll}-1 & 829 & 971.971\end{array}$ $+1000976976$ $+1828829000$ +0 111004646 $+1000837000$ $+1000879225$ $+3000961000$ $+1000836837$ $+3000 \quad 024841$ $+3000841228$ $+1000228228$ $+0203000148$ $+9002261822$ +0203000436 +0111004 978 $+1000882228$ +0 203000000 $+1000910000$
$+3952745865$ $+3197844883$ $+3204859889$ +9001869215 $+1000884000$ $+4000807000$ $+3000865000$ $+1000874 \quad 220$ $+1000875221$ $+3000866000$ $+3000867000$ $+2.223000000$ $+2896000000$ $+1000223000$ $+3000868.000$ $+2201219000$ $\begin{array}{llll}-4 & 954766954\end{array}$ +4965814895 $+1245000000$ $+4966813824$ $+2826827000$ $+2826827000$ $+3000892246$ $+1000246000$ $+1000246000$ -3 829700,829 +0 111005629 $+4000901902$ $+1000830000$ $+1833834000$ $+3000960225$ $\begin{array}{lllll}-3 & 824 & 085 & 828\end{array}$ $+1000880226$ $+4832773838$ $+3000861000$ $+2963863000$ +0 203000977 $+0454000000$ +0 410822827

$+1828829000$ $\begin{array}{llll}-1 & 243 & 211 & 211\end{array}$ $+7945000991$ $+1000911912$
$+3952748866$ $+3198847884$ $+4197804890$ $+3864883000$ $+3000865000$ $+2218000000$ $+1000885000$ $+2851854000$ $+2852857000$ $+3000892222$ $+1000876222$ $+4000811223$ $+4000814896$ $+3000020223$ $+1000877223$ $+3000757000$ +0 111010570 $+4964811000$ $+3000020245$ $+4967816825$ $+4000817000$ $+4000 \cdot 817000$ $+3828202000$ $+3000867246$ $+3000.952000$ +0 101004624 +9001975903 $\begin{array}{llll}-4 & 243 & 951 & 824\end{array}$ $+1000831832$ $+1000835000$ $+2206838000$ +0 1111004660 $\begin{array}{lllll}-3 & 824 & 089 & 833\end{array}$ $+3000 \quad 024839$ $+1000227000$ $+4000774000$ +0 070945001 $+8194000916$

$+1000830000$ +0111004 1886 +9001901970 +0 203000.171
$+3952750867$ $+4198807891$ $+1000870216$ $+1000871217$ $+3000864000$ $+3000019000$ $+3000866000$ $+4000811222$ $+3895893000$ $+2853859000$ $+2856859000$ $+2223000.000$ $+3895203000$ $+2197215000$ $+3000952000$ $+2954956964$ $+2000895000$ $+3956203.000$ $+4968 \times 18826$ $+2246000000$ $+2828000000$ $+1000246000$ $+3827204000$ $+3000761246$ $+1829830000$ $+3952.951834$ $+3000959000$ $+1000836837$ $+3000860000$ $+1828829000$ +0 11.1 004667 $+1000837840$ $+1000881227$ $+3000840.000$ $+0203000451$ $+0203000273$

$+1000831000$ $+9004211908$ $+9001901907$ 
Current "Best". Values of Input Parameters Por Irradiation at $46.1^{\circ} \mathrm{C}$ a. ia Shutdom Fransient Reactivity at $20^{\circ} \mathrm{C}$

$\begin{array}{llll}1 & 001 & 6 & +3155000071 \\ 2 & 007 & 6 & +0000000000 \\ 3 & 013 & 6 & +0000000000 \\ 4 & 019 & 6 & +1588300044 \\ 5 & 025 & 6 & +3632100044 \\ 6 & 031 & 6 & +6000000027 \\ 7 & 037 & 6 & +0000000000 \\ 3 & 043 & 6 & +1455000028 \\ 7 & 049 & 6 & +9208000028 \\ 10 & 055 & 6 & +2600000029 \\ 11 & 061 & 6 & +0000000000 \\ 12 & 067 & 6 & +2300000027 \\ 13 & 073 & 6 & +2050000052 \\ 14 & 079 & 6 & +5800000048 \\ 15 & 085 & 6 & +1530000048 \\ 16 & 091 & 6 & +0000000000 \\ 17 & 097 & 6 & ++5996000028 \\ 13 & 103 & 6 & +9763000028 \\ 19 & 109 & 6 & +0000000000 \\ 20 & 115 & 6 & +2410000026 \\ 21 & 121 & 6 & +2590000050 \\ 22 & 127 & 6 & +5000000027 \\ 23 & 133 & 6 & +2390000052 \\ 24 & 139 & 6 & +1000000050 \\ 25 & 145 & 2 & +0000000941\end{array}$

$+0000000000$

$+0000000000$

$+000.0000000$

$+0000000000$

$+0000006000$

$+0000000000$

$+1664800041$

$+3442400044$

$+51000000.26$

$+25980.00028$

$+59550.00030$

$+6000000027$

$+0000000000$

$+2443000029$

$+8545000029$

$+3331000028$

$+1030000029$

$+2050000052$

$+2000000047$

$+1890000048$

$+000000000.0$

$+0000000000$

$+1295300029$

$+9650000027$

$+2822000028$

$+3060000050$

$+2360000052$

$+2400000052$

$+5490000073$

$+0000600000$

$+0000600000$

$+0000<00000$

$+2881.00045$

$+0000 C 00000$

$+1268=00029$

$+9160600027$

$+28160.00028$

$+4683600028$

$+0000600000$

$+29490100028$

+85450.00029 .

$+20500.00052$

$+20000.00047$

$+2000[-00048$

$+0000600000$

$+15176.00028$

$+70000.00026$

$+5317000026$

$+26870.00028$

$+5000600027$

$+23700.00052$

$+2900100050$

$+2410000052$

$+239000052$

$+9204000072$

$+4323050073$

$+0000000000$

$+0000000000$

$+2108400045$

$+1455000028$

$+7000000026$

$+5.100000026$

$+2598000028$

$+2300000027$

$+2.830000031$

$+0000000000$

$+1331000029$

$+6100000048$

$+2000000047$

$+0000000000$

$+0000000000$

$+2410000026$

$+2531000032$

$+0000000000$

$+3470000028$

$+5000000027$

$+2370000052$

$+1014300056$

$+0000000000$

$+0000000000$

$+0000000000$

$+9625000045$

$+2310000026$

$+231000026$

$+2461000032$

$+3458000028$

$+0000000000$

+0000000000 .

$+4683000028$

+4683000028
+2800000024

$+6100000048$

$+2000000047$

$+0000000000$

$+0000000000$

$+6000000027$

$+0000000000$

$+1517000028$

$+2470000050$

$+5000000027$

$+2380000052$

$+1000000070$

$+3300000025$

$+1800000025$

Selested Cooling Times for Transient Calculations

251516

27157

$+0000000000$

$+7200100053$

$+1440000054$

$+25200100054$

$+14400100055$

$+720000005$

$+1080000055$

$+57600$

$+5400000055$

$+7200000055$

$+1080000056$

$+3600000054$

$+1800000055$

$+1800000056$

$+4320000054$

$+2520000055$

$+3600000056$

$+1080000057$ 
REVISED EXPRESSIONS FOR ISOTOPIC NUMBER DENSITY AND FISSION

Revised expressions which minimize round-off errors in code calculations for small flux-time steps are presented. Alternative expressions are given in some cases. The quantity $\Delta \mathrm{N}_{k}^{i, j}$ is the change in number density of isotope $i, j$ during the $k^{\text {th }}$ irradiation step. In terms involving multiple summations, the summation $\sum_{a, b} \ldots$ means a sum over all values of $a, b, \ldots$ from zero to $n$, subject to the condition that $a+b+\ldots=n$. The expressions are exact.

\section{General Expressions}

$$
\begin{aligned}
& \Delta N_{k}^{25}=N_{k-1}^{25} \sum_{n=1}^{\infty} \frac{t_{k}^{n}}{n !}\left(-\psi_{k}^{25}\right)^{n} \\
& \Delta N_{k}^{26}=N_{k-1}^{25} \sigma_{k k}^{25} \phi_{k} t_{k}\left[\sum_{n=0}^{\infty} \frac{t_{k}^{n}}{(n+1) !}\left(\psi_{k}^{26}-\psi_{k}^{25}\right)^{n}\right] e^{-\psi_{k}^{28} t_{k}}+N_{k-1}^{26} \sum_{n=1}^{\infty} \frac{t_{k}^{n}}{n !} \\
& \Delta N_{k}^{26}=N_{k-1}^{25}{ }_{\gamma k}^{25} \phi_{k} \sum_{k}^{\infty} \frac{t_{k}^{n}}{(n+1) !} \sum_{a, b}\left(-\psi_{k}^{26}\right)^{a}\left(-\psi_{k}^{25}\right)^{b}+N_{k-1}^{26} \sum_{n=1}^{\infty} \frac{t_{k}^{n}}{n !}\left(-\psi_{k}^{26}\right)^{n} \\
& \Delta N_{k}^{27}=\sigma_{\gamma k}^{26} \phi_{k} t_{k}\left\{N_{k-1}^{25} \sigma_{\gamma k}^{25} \phi_{k}^{t} k\left[\sum_{n=0}^{\infty} \frac{t_{k}^{n}}{(n+2) !} \sum_{a, b}\left(\psi_{k}^{27}-\psi_{k}^{26}\right)^{a}\left(\psi_{k}^{27}-\psi_{k}^{25}\right)^{b}\right]\right.
\end{aligned}
$$

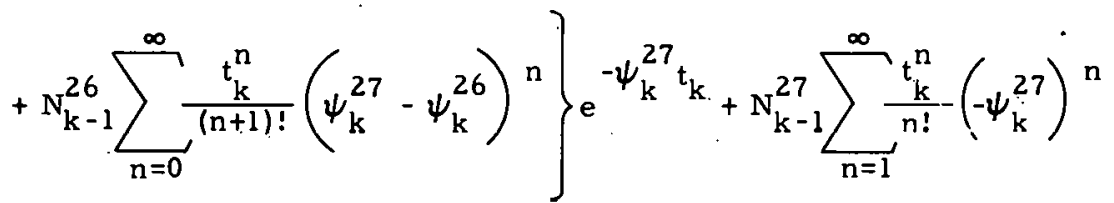

$$
\begin{aligned}
& \Delta N_{k}^{27}=F_{\gamma k}^{26} \phi_{k} t_{k}\left\{N_{k-1}^{25}-\sigma_{\gamma k}^{25} \phi_{k}^{t} \sum_{n=0}^{\infty} \frac{t_{k}^{n}}{(n+2) !} \sum_{a, b, c}\left(-\psi_{k}^{27}\right)^{a}\left(-\psi_{k}^{26}\right)^{b}\left(-\psi_{k}^{25}\right)^{c}\right. \\
& \left.+N_{k-1}^{26} \sum_{n=0}^{\infty} \frac{t_{k}^{n}}{(n+1) !} \sum_{a, b}\left(-\psi_{k}^{27}\right)^{a}\left(-\psi_{k}^{26}\right)^{b}\right\}+N_{k-1}^{27} \sum_{n=1}^{\infty} \frac{t_{k}^{n}}{n^{!}}\left(-\psi_{k}^{27}\right)^{n} \\
& \Delta N_{k}^{37}=\lambda^{27} t_{k}\left\{{ } _ { \gamma k } ^ { 2 6 } \phi _ { k } ^ { t } \left\{N_{k-1}^{25}{ }_{\gamma k}^{25} \phi_{k}^{t} \sum_{n=0}^{\infty} \frac{t_{k}^{n}}{(n+3) !} \sum_{a, b, c}\left(\psi_{k}^{37}-\psi_{k}^{27}\right)^{a}\left(\psi_{k}^{37}-\psi_{k}^{26}\right)^{b}\left(\psi_{k}^{37}-\psi_{k}^{25}\right)^{c}\right.\right.
\end{aligned}
$$




$$
\begin{aligned}
& \left.+N_{k-1}^{26} \sum_{n=0}^{\infty} \frac{t_{k}^{n}}{(n+2) !} \sum_{a, b}\left(\psi_{k}^{37}-\psi_{k}^{27}\right)^{a}\left(\psi_{k}^{37}-\psi_{k}^{26}\right)^{b}\right\} \\
& \left.+N_{k-1}^{27} \sum_{n=0}^{\infty} \frac{t_{k}^{n}}{(n+1) !}\left(\psi_{k}^{37}-\psi_{k}^{27}\right)^{n}\right\} e^{-\psi_{k}^{37} t_{k}}+N_{k-1}^{37} \sum_{n=1}^{\infty} \frac{t_{k}^{n}}{n !}\left(-\psi_{k}^{37}\right)^{n} \\
& \Delta N_{k}^{37}=\lambda^{27} t_{k}\left\{\sigma _ { \gamma k } ^ { 2 6 } \phi _ { k } t _ { k } \left\{N_{k-1}^{25} \sigma_{\gamma k}^{25} \phi_{k} t_{k} \sum_{n=0}^{\infty} \frac{t_{k}^{n}}{(n+3) !} \sum_{a, b, c, d}\left(-\psi_{k}^{37}\right)^{a}\left(-\psi_{k}^{27}\right)^{b}\left(-\psi_{k}^{26}\right)^{c}\left(-\psi_{k}^{25}\right)^{d}\right.\right. \\
& \left.+N_{k-1}^{26} \sum_{n=0}^{\infty} \frac{t_{k}^{n}}{(n+2) !} \sum_{a, b, c}\left(-1 k_{k}^{37}\right)^{a}\left(-\psi_{k}^{27}\right)^{b}\left(-\psi_{k}^{26}\right)^{c}\right\} \\
& \left.+N_{k-1}^{27} \sum_{n=0}^{\infty} \frac{t_{k}^{n}}{(n+1) !} \sum_{a, b}\left(-\psi_{k}^{37}\right)^{a}\left(-\psi_{k}^{27}\right)^{b}\right\}+N_{k-1}^{37} \sum_{n=1}^{\infty} \frac{t_{k}^{n}}{n !}\left(-\psi_{k}^{37}\right)^{n} \\
& \Delta N_{k}^{28}=N_{k-1}^{28} \sum_{n=1}^{\infty} \frac{t_{k}^{n}}{n !}\left(-\psi_{k}^{28}\right)^{n} \\
& \Delta N_{k}^{39}=N_{k-1}^{28} \sigma_{\gamma k}^{28} \phi_{k} t_{k}\left[\sum_{n=0}^{\infty} \frac{t_{k}^{n}}{(n+1) !}\left(\psi_{k}^{39}-\psi_{k}^{28}\right)^{n}\right] e^{-\psi_{k}^{39} t_{k}}+N_{k-1}^{39} \sum_{n=0}^{\infty} \frac{t_{k}^{n}}{n !}\left(-\psi_{k}^{39}\right)^{n} \\
& =N_{k-1}^{28} \sigma_{\gamma k}^{28} \phi_{k} t_{k} \sum_{n=0}^{\infty} \frac{t_{k}^{n}}{(n+1) !} \sum_{a, b}\left(-\psi_{k}^{39}\right)^{a}\left(-\psi_{k}^{28}\right)^{b}+N_{k-1}^{39} \sum_{n=1}^{\infty} \frac{t_{k}^{n}}{n !}\left(-\psi_{k}^{39}\right)^{n}(C 10) \\
& \Delta N_{k}^{49}=\lambda^{39} t_{k}\left\{N_{k-1}^{28} \sigma_{\gamma k}^{28} \phi_{k} t_{k} \sum_{n=0}^{\infty} \frac{t_{k}^{n}}{(n+2) !} \sum_{a, b}\left(\psi_{k}^{49}-\psi_{k}^{39}\right)^{a}\left(\psi_{k}^{49}-\psi_{k}^{28}\right)^{b}\right. \\
& \left.+N_{k-1}^{39} \sum_{n=0}^{\infty} \frac{t_{k}^{n}}{(n+1) !}\left(\psi_{k}^{49}-\psi_{k}^{39}\right)^{n}\right\} e^{-\psi_{k}^{49} t_{k}}+N_{k-1}^{49} \sum_{n=1}^{\infty} \frac{t_{k}^{n}}{n !}\left(-\psi_{k}^{49}\right)^{n}
\end{aligned}
$$




$$
\begin{aligned}
& \Delta \mathbb{N}_{k}^{49}=\lambda^{39} t_{k}\left\{\dot{N}_{k-1}^{28} \sigma_{\gamma k}^{28} \phi_{k} t_{k} \sum_{n=0}^{\infty} \frac{t_{k}^{n}}{(n+2) !} \sum_{a, b, c}\left(-\psi_{k}^{49}\right)^{a}\left(-\psi_{k}^{39}\right)^{b} \cdot\left(-\psi_{k}^{28}\right)^{c}\right. \\
& \left.+N_{k-1}^{39} \sum_{n=0}^{\infty} \frac{i_{k}^{n}}{(11+1) !} \sum_{a, b}\left(-\psi_{k}^{49}\right)^{a} \cdot\left(-\psi_{k}^{39}\right)^{b}\right\}+N_{k-1}^{49} \sum_{n=1}^{\infty} \frac{t_{k}^{n}}{n !}\left(-\psi_{k}^{49}\right)^{n} \quad \text { (C12) } \\
& \Delta N_{k}^{40}=\sigma_{\gamma k}^{49} \phi_{k} t_{k}\left\{\lambda ^ { 3 9 } t _ { k } \left\{N_{k-1}^{28} \sigma_{\gamma k}^{28} \phi_{k} t_{k} \sum_{n=0}^{\infty} \frac{t_{k}^{n}}{(n+3) !} \sum_{a, b, c}\left(\psi_{k}^{40}-\psi_{k}^{49}\right)^{a}\left(\psi_{k}^{40}-\psi_{k}^{39}\right)^{b}\left(\psi_{k}^{40}-\psi_{k}^{28}\right)^{c}\right.\right. \\
& \left.+N_{k-1}^{39} \sum_{n=0}^{\infty} \frac{t_{k}^{n}}{(n+2) !} \sum_{a, b}\left(\psi_{k}^{40}-\psi_{k}^{49}\right)^{a}\left(\psi_{k}^{40}-\psi_{k}^{39}\right)^{b}\right\} \\
& \left.+N_{k-1}^{49} \sum_{n=0}^{\infty} \frac{t_{k}^{n}}{(n+1) !}\left(\psi_{k}^{40}-\psi_{k}^{49}\right)^{n}\right\} e^{-\psi_{k}^{40} t_{k}}+N_{k-1}^{40} \sum_{n=1}^{\infty} \frac{t_{k}^{n}}{n !}\left(-\psi_{k}^{40}\right)^{n} \\
& \Delta N_{k}^{40}=\sigma_{\gamma k}^{49} \phi_{k} t_{k}\left\{\lambda ^ { 3 9 } t _ { k } \left\{N_{k-1}^{28} \sigma_{\gamma k}^{28} \phi_{k} t_{k} \sum_{n=0}^{\infty} \frac{t_{k}^{n}}{(n+3) !} \sum_{a, b, c, d}\left(-\psi_{k}^{40}\right)^{a}\left(-\psi_{k}^{49}\right)^{b}\left(-\psi_{k}^{39}\right)^{c}\left(-\psi_{k}^{28}\right)^{d}\right.\right. \\
& \left.+N_{k-1}^{39} \sum_{n=0}^{\infty} \frac{t_{k}^{n}}{(n+2) !} \sum_{a, b, c}\left(-\psi_{k}^{40}\right)^{a}\left(-\psi_{k}^{49}\right)^{b}\left(-\psi_{k}^{39}\right)^{c}\right\} \\
& \left.+N_{k=1}^{49} \sum_{n=0}^{\infty} \frac{t_{k}^{n}}{(n+1) !} \sum_{a, b}\left(-\psi_{k}^{40}\right)^{a}\left(-\psi_{k}^{49}\right)^{b}\right\}+N_{k-1}^{40} \sum_{n=1}^{\infty} \frac{t_{k}^{n}}{n !}\left(-\psi_{k}^{40}\right)^{n} \\
& \text { (C14) } \\
& \Delta \mathrm{N}_{\mathrm{k}}^{41}=\sigma_{\gamma \mathrm{k}}^{40} \phi_{\mathrm{k}} \mathrm{t}_{\mathrm{k}} \int\left(-_{\gamma \mathrm{k}}^{49} \phi_{\mathrm{k}} \mathrm{t}_{\mathrm{k}}\left\{\lambda ^ { 3 9 } \mathrm { t } _ { \mathrm { k } } \left\{\mathrm{N}_{\mathrm{k}-1^{-\sigma_{k k}}}^{28} \phi_{\mathrm{k}} \mathrm{t}_{\mathrm{k}} \sum_{\mathrm{n}=0}^{\infty} \frac{\mathrm{t}_{\mathrm{k}}^{\mathrm{n}}}{(\mathrm{n}+4) !}\right.\right.\right. \\
& \sum_{a, b, c, d}\left(\psi_{k}^{41}-\psi_{k}^{40}\right)^{a}\left(\psi_{k}^{41}-\psi_{k}^{49}\right)^{b}\left(\psi^{41}-\psi^{39}\right) c\left(\psi^{41}-\psi^{28}\right)^{d} \\
& \left.+N_{k-1}^{39} \sum_{n=0}^{\infty} \frac{t_{k}^{n}}{(n+3) !} \sum_{a, b, c}\left(\psi_{k}^{41}-\psi_{k}^{40}\right)^{a}\left(\psi_{k}^{41}-\psi_{k}^{49}\right)^{b}\left(\psi_{k}^{41}-\psi_{k}^{39}\right) c\right\}
\end{aligned}
$$

2.7 


$$
\begin{aligned}
& \left.+N_{k-1}^{49} \sum_{n=0}^{\infty} \frac{t_{k}^{n}}{(n+2) !} \sum_{a, b}\left(\psi_{k}^{41}-\psi_{k}^{40}\right)^{a}\left(\psi_{k}^{40}-\psi_{k}^{49}\right)^{b}\right\} \\
& \left.\left.+N_{k-1}^{40} \sum_{n=0}^{\infty} \frac{t_{k}^{n}}{(n+1) !}\left(\psi_{k}^{41}-\psi_{k}^{40}\right)^{n}\right)\right] e^{-\psi_{k}^{41} t_{k}}+N_{k-1}^{41} \sum_{n=1}^{\infty} \frac{t_{k}^{n}}{n !}\left(-\psi_{k}^{41}\right)^{n} \\
& \Delta N_{k}^{41}=\sigma_{\gamma k}^{40} \phi_{k} t_{k} \int\left(-\sigma_{\gamma k}^{49} \phi_{k} t_{k}\left\{\lambda ^ { 3 9 } t _ { k } \left\{N_{k-1}^{28} \sigma_{\gamma k}^{28} \phi_{k} t_{k} \sum_{n=0}^{\infty} \frac{t_{k}^{n}}{(n+4) !}\right.\right.\right. \\
& \sum_{a, b, c, d, e}\left(-\psi_{k}^{41}\right)^{a}\left(-\psi_{k}^{40}\right)^{b}\left(-\psi_{k}^{49}\right)^{c}\left(-\psi_{k}^{39}\right)^{d}\left(-\psi_{k}^{28}\right)^{e} \\
& \left.+N_{k-1}^{39} \sum_{n=0}^{\infty} \frac{i_{k}^{n}}{(n+3) !} \sum_{a, b, c, d}\left(-\psi_{k}^{41}\right)^{a}\left(-\psi_{k}^{40}\right)^{b}\left(-\psi_{k}^{49}\right)^{c}\left(-\psi_{k}^{39}\right)^{d}\right\} \\
& \left.+N_{k-1}^{49} \sum_{n=0}^{\infty} \frac{t_{k}^{n}}{(n+2) !} \sum_{a, b, c}\left(-\psi_{k}^{41}\right)^{a}\left(-\psi_{k}^{40}\right)^{b}\left(-\psi_{k}^{49}\right)^{c}\right\} \\
& \left.+N_{k-1}^{40} \sum_{n=0}^{\infty} \frac{t_{k}^{11}}{(n+1) !} \sum_{a, b}\left(-\psi_{k}^{41}\right)^{a} \cdot\left(-\psi_{k}^{40}\right)^{b}\right) \\
& +N_{k-1}^{41} \sum_{n=1}^{\infty} \frac{t_{k}^{n}}{n !}\left(-\psi_{k}^{41}\right)^{n} \\
& \Delta \mathrm{N}_{\mathrm{k}}^{42}={ }_{\gamma \mathrm{k}}^{41} \phi_{\mathrm{k}} \mathrm{t}_{\mathrm{k}}\left\{\int \sigma _ { \gamma \mathrm { k } } ^ { 4 0 } \phi _ { \mathrm { k } } \mathrm { t } _ { \mathrm { k } } \int \int \sigma _ { \gamma \mathrm { k } } ^ { 4 9 } \phi _ { \mathrm { k } } \mathrm { t } _ { \mathrm { k } } \left\{\lambda ^ { 3 9 } \mathrm { t } _ { \mathrm { k } } \left\{\sigma_{\gamma \mathrm{k}}^{28} \phi_{\mathrm{k}} \mathrm{t}_{\mathrm{k}} \mathrm{N}_{\mathrm{k}-1}^{28} \sum_{\mathrm{n}=0}^{\infty} \frac{t_{\mathrm{k}}^{\mathrm{n}}}{(\mathrm{n}+5) !}\right.\right.\right. \\
& \sum_{a, b, c, d, e ; f}\left(-\psi_{k}^{42}\right)^{a}\left(-\psi_{k}^{41}\right)^{b}\left(-\psi_{k}^{40}\right)^{c}\left(-\psi_{k}^{49}\right)^{d}\left(-\psi_{k}^{39}\right)^{e}\left(-\psi_{k}^{28}\right)^{f} \\
& \left.+N_{k-1}^{39} \sum_{n=0}^{\infty} \frac{t_{k}^{n}}{(n+4) !} \sum_{a, b, c, d, e}\left(-\psi_{k}^{42}\right)^{a}\left(-\psi_{k}^{41}\right)^{b} \cdot\left(-\psi_{k}^{40}\right)^{c}\left(-\psi_{k}^{49}\right)^{d}\left(-\psi_{k}^{39}\right)^{e}\right\}
\end{aligned}
$$

28 


$$
\begin{aligned}
& \left.+N_{k-1}^{49} \sum_{n=0}^{\infty} \frac{t_{k}^{n}}{(n+3) !} \sum_{a, b, c, d}\left(-\psi_{k}^{42}\right)^{a}\left(-\psi_{k}^{41}\right)^{b}\left(-\psi_{k}^{40}\right)^{c}\left(-\psi_{k}^{49}\right)^{d}\right\} \\
& \left.\because \quad+N_{k-1}^{40} \sum_{n=0}^{\infty} \frac{t_{k}^{n}}{(n+2) !} \sum_{a, b, c}\left(-\psi_{k}^{42}\right)^{a}\left(-\psi_{k}^{41}\right)^{b}\left(-\psi_{k}^{40}\right)^{c}\right) \\
& \left.+N_{k-1}^{41} \sum_{n=0}^{\infty} \frac{t_{k}^{n}}{(n+1) !} \sum_{a, b}\left(-\psi_{k}^{42}\right)^{a}-\psi_{k}^{41} b\right]+N_{k-1}^{42} \sum_{n=1}^{\infty} \frac{t_{k}^{n}}{n !}\left(-\psi_{k}^{42}\right)^{n} \\
& \mathrm{~F}_{\mathrm{k}}^{25}=\frac{\left(\sigma_{\mathrm{ak}}^{25}-\sigma_{\gamma \mathrm{k}}^{25}\right) \phi_{\mathrm{k}}}{\psi_{\mathrm{k}}^{25}} \Delta \mathrm{N}_{\mathrm{k}}^{25} \\
& F_{k}^{28}=-\frac{\left(\sigma_{\mathrm{ak}}^{28}-{ }^{28}\right) \phi_{\mathrm{k}}}{\psi_{\mathrm{k}}^{28}} \Delta \mathrm{N}_{\mathrm{k}}^{28}=-\frac{\delta_{\mathrm{k}}^{28} \phi_{\mathrm{k}}}{\psi_{\mathrm{k}}^{28}} \Delta \mathrm{N}_{\mathrm{k}}^{28} \\
& F_{k}^{49}=\left(\sigma_{a k}^{49}-\sigma_{\gamma k}^{49}\right) \phi_{k} t_{k}\left\{\lambda ^ { 3 9 } t _ { k } \left\{\sigma_{\gamma k}^{28} \phi_{k} t_{k} N_{k-1}^{28} \sum_{n=0}^{\infty} \frac{t_{k}^{n}}{(n+3) !} \sum_{a, b, c}\left(-\psi_{k}^{49}\right)^{a}\left(-\psi_{k}^{39}\right)^{b}\left(-\psi_{k}^{28}\right)^{c}\right.\right. \\
& \left.\left.+N_{k-1}^{39} \sum_{n=0}^{\infty} \frac{t_{k}^{n}}{(n+2) !} \sum_{a, b}\left(-\psi_{k}^{49}\right)^{a}\left(-\psi_{k}^{39}\right)^{b}\right\}+N_{k-1}^{49} \sum_{n=0}^{\infty} \frac{t_{k}^{n}}{(n+1) !}\left(-\psi_{k}^{49}\right)^{n}\right\}
\end{aligned}
$$

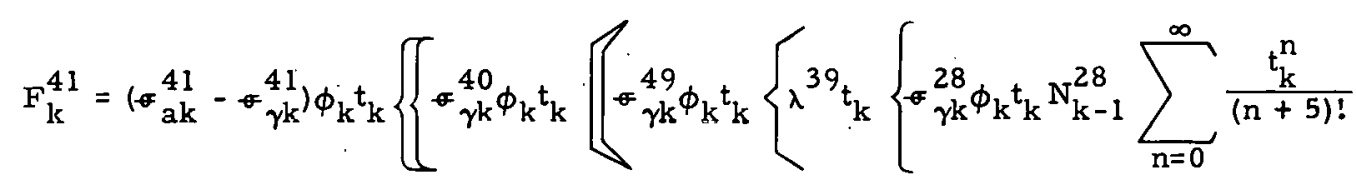

$$
\begin{aligned}
& \sum_{a, b, c, d, e}\left(-\psi_{k}^{41}\right)^{a}\left(-\psi_{k}^{40}\right)^{b}\left(-\psi_{k}^{49}\right)^{c}\left(-\psi_{k}^{39}\right)^{d}\left(-\psi_{k}^{28}\right)^{e} \\
& \left.+\mathrm{N}_{\mathrm{k}-1}^{39} \sum_{\mathrm{n}=0}^{\infty} \frac{\mathrm{t}_{\mathrm{k}}^{\mathrm{n}}}{(\mathrm{n}-4) !} \sum_{\mathrm{a}, \mathrm{b}, \mathrm{c}, \mathrm{d}}\left(-\psi_{\mathrm{k}}^{41}\right)^{\mathrm{a}} \cdot\left(-\psi_{\mathrm{k}}^{40}\right)^{\mathrm{b}}\left(-\psi_{\mathrm{k}}^{49}\right)^{\mathrm{c}}\left(-\psi_{\mathrm{k}}^{39}\right)^{\mathrm{d}}\right\}
\end{aligned}
$$

*Expression ( $\mathrm{Cl}$ ), for the change in concentration of $\mathrm{Pu}-242$ during the $\mathrm{k}^{\text {th }}$ irradiation step, has no corresponding expression in Appendix A because, in the exponential form of Appendix $A$, its length would be prohibitive. Equation ( $\mathrm{C} 17$ ) illustrates the extension to the higher isotopes of the summation form of the expressions and is of practical value since isotopic plutonium measure ments on the mass spectrometer give $\mathcal{P}-242$ as well as the lighter plutonium isotopes. 


$$
\begin{aligned}
& \left.+N_{k-1}^{49} \sum_{n=0}^{\infty} \frac{t_{k}^{n}}{(n+3) !} \sum_{a, b, c}\left(-\psi_{k}^{41}\right)^{a}\left(-\psi_{k}^{40}\right)^{b}\left(-\psi_{k}^{49}\right)^{c}\right\} \\
& \left.\left.\left.\left.+N_{k-1}^{40} \sum_{n=0}^{\infty} \frac{t_{k}^{n}}{(n+2) !} \sum_{a, b}\left(-\psi_{k}^{41}\right)^{a}\left(-\psi_{k}^{40}\right)^{b}\right)\right]+N_{k-1}^{41} \sum_{n=0}^{\infty} \frac{t_{k}^{n}}{(n+1) !}\left(-\psi_{k}^{41}\right)^{n}\right\}\right\}(C 21) \\
& \Delta N_{k}^{I}=\sum_{u, v} y_{I}^{u, v_{F} u, v} \sum_{n=0}^{\infty} \frac{t_{k}^{n}}{(n+1) !}\left(-\psi_{k}^{I}\right)^{n}+N_{k-1}^{I} \sum_{n=1}^{\infty} \frac{t_{k}^{n}}{n !}\left(-\psi_{k}^{I}\right)^{n} \\
& \text { (C22) } \\
& \Delta N_{k}^{X e}=\sum_{u, v} y_{X e}^{u, v} F_{k}^{u, v} \sum_{n=0}^{\infty} \frac{t_{k}^{n}}{(n+1) !}\left(-\psi_{k}^{X e}\right)^{n} \\
& +\lambda^{I} t_{k}\left[\sum_{u, v} y_{I}^{u, v} v_{k}^{u, v} \sum_{n=0}^{\infty} \frac{t_{k}^{n}}{(n+2) !} \sum_{a, b}\left(-\psi_{k}^{X e}\right)^{a}\left(-\psi_{k}^{I}\right)^{b}\right. \\
& \left.+N_{k-1}^{I} \sum_{n=0}^{\infty} \frac{t_{k}^{n}}{(n+1) !} \sum_{a, b}\left(-\psi_{k}^{X e}\right)^{a}\left(-\psi_{k}^{I}\right)^{b}\right] \\
& +N_{k=1}^{X e} \sum_{n-1}^{\infty} \frac{t_{k}^{n}}{n !}\left(-\psi_{k}^{X e}\right)^{n} \\
& \text { (C23) } \\
& \Delta N_{k}^{N d}=\sum_{u, v} y_{N d}^{u, v} \mathbf{F}_{k}^{u, v} \sum_{n=0}^{\infty} \frac{t_{k}^{n}}{(n+1) !}\left(-\psi_{k}^{N d}\right)^{n}+N_{k-1}^{N d} \sum_{n=1}^{\infty} \frac{t_{k}^{n}}{n !}\left(-\psi_{k}^{N d}\right)^{n} \\
& \text { (C24) } \\
& \Delta \mathrm{N}_{\mathrm{k}}^{\mathrm{Pm}}=\sum_{\mathrm{u}, \mathrm{v}} \mathrm{y}_{\mathrm{Pm}_{\mathrm{k}}}^{\mathrm{u}, \mathrm{v}_{\mathrm{F}}^{\mathrm{u}}, \mathrm{v}} \sum_{n=0}^{\infty} \frac{t_{\mathrm{k}}^{\mathrm{n}}}{(n+1) !}\left(-\psi_{\mathrm{k}}^{\mathrm{Pm}}\right)^{\mathrm{n}} \\
& +\lambda^{N d_{t_{k}}}\left[\sum_{u, v} y_{N d}^{u, v} F_{k}^{u, v} \sum_{n=0}^{\infty} \frac{t_{k}^{n}}{(n+2) !} \sum_{a, b}\left(-\psi_{k}^{P m}\right)^{a}\left(-\psi_{k}^{N d}\right)^{b}\right.
\end{aligned}
$$

30 


$$
\begin{aligned}
& \left.+N_{k-1}^{N d} \sum_{n=0}^{\infty} \frac{t_{k}^{n}}{(n+1) !} \sum_{a, b}\left(-\psi_{k}^{P m}\right)^{a}\left(-\psi_{k}^{N d}\right)^{b}\right]+N_{k-1}^{P m} \sum_{n=1}^{\infty} \frac{t_{k}^{n}}{n !}\left(-\psi_{k}^{P m}\right)^{n} \\
& \Delta N_{k}^{S m}=\sum_{u, v} y_{S m}^{u, v} F_{k}^{u, v} \sum_{n=0}^{\infty} \frac{t_{k}^{n}}{(n+1) !}\left(-\psi_{k}^{S m}\right)^{n} \\
& +\lambda^{P m_{t}}\left\{\sum_{u, v} y_{P m_{k}^{u}}^{u, v} \sum_{n=0}^{u, v} \frac{t_{k}^{n}}{(n+2) !} \sum_{a, b}^{\infty}\left(-\psi_{k}^{S m}\right)^{a}\left(-\psi_{k}^{P m}\right)^{b}\right. \\
& +\lambda^{N d_{t}}\left[\sum_{u, v} y_{N d}^{u, v} F_{k}^{u, v} \sum_{n=0}^{\infty} \frac{t_{k}^{n}}{(n+3) !} \sum_{a, b, c}\left(-\psi_{k}^{S m}\right)^{a}\left(-\psi_{k}^{P m}\right)^{b}\left(-\psi_{k}^{N d}\right)^{c}\right. \\
& \left.+N_{k-1}^{N d} \sum_{n=0}^{\infty} \frac{t_{k}^{n}}{(n+2) !} \sum_{a, b, c}\left(-\psi_{k}^{S m}\right)^{a}\left(-\psi_{k}^{P m}\right)^{b}\left(-\psi_{k}^{N d}\right)^{c}\right] \\
& \left.+N_{k-1}^{P m} \sum_{n=0}^{\infty} \frac{t_{k}^{n}}{(n+1) !} \sum_{a, b}\left(-\psi_{k}^{S m}\right)^{a}\left(-\psi_{k}^{P m}\right)^{b}\right\} \\
& +N_{k-1}^{S m} \sum_{n=1}^{\infty}-\frac{t_{k}^{n}}{n !}\left(-\psi_{k}^{S m}\right)^{n}
\end{aligned}
$$

Expressions for Zero-Flux Case

For the special case of zero flux, expressions (C1) through (C26) reduce to the following:

$\Delta \mathrm{N}_{\mathrm{k}}^{25}=0$

(C27)

$$
\Delta \mathrm{N}_{\mathrm{k}}^{26}=0
$$

$$
\begin{gathered}
\Delta \mathrm{N}_{k}^{27}=\mathrm{N}_{\mathrm{k}-1}^{27} \sum_{\mathrm{n}=1}^{\infty} \frac{\mathrm{t}_{\mathrm{k}}^{\mathrm{n}}}{\mathrm{n} !}\left(-\lambda^{27}\right)^{\mathrm{n}} \\
\Delta \mathrm{N}_{\mathrm{k}}^{37}=-\Delta \mathrm{N}_{\mathrm{k}}^{27} \\
\quad \Delta \mathrm{N}_{\mathrm{k}}^{28}=0
\end{gathered}
$$

31 


$$
\begin{aligned}
& \Delta \mathrm{N}_{\mathrm{k}}^{39}=\mathrm{N}_{\mathrm{k}-1}^{39} \sum_{\mathrm{n}=1}^{\infty} \frac{\mathrm{t}_{\mathrm{k}}^{\mathrm{n}}}{\mathrm{n} !}\left(-\lambda^{39}\right)^{\mathrm{n}} \cdots \\
& \Delta \mathrm{N}_{\mathrm{k}}^{49}=-\Delta \mathrm{N}_{\mathrm{k}}^{39} \\
& \Delta N_{k}^{40}=0 \\
& \left.\Delta N_{k}^{41}=N_{k-1}^{41} \sum_{n=1}^{\infty} \frac{t_{k}^{n}}{n !}(-\lambda)^{41}\right)^{n} \\
& \Delta \mathrm{N}_{\mathrm{k}}^{42}=0 \\
& F_{k}^{25}=0 \\
& F_{k}^{28}=0 . \\
& F_{k}^{49}=0 \\
& F_{k}^{41}=0 \\
& \Delta N_{k}^{I}=N_{k-1}^{I} \sum_{n=1}^{\infty} \frac{t_{k}^{n}}{n !}(-\lambda I)^{n} \\
& \Delta N_{k}^{X e}=\lambda t_{b_{k}} N_{k-1}^{I} \sum_{n=0}^{\infty} \frac{t_{k}^{n}}{(n+1) !} \sum_{a, b}(-\lambda X e)^{a}(-\lambda)^{b}+N_{k-1}^{X e} \sum_{n=1}^{\infty} t_{k}^{n} \cdot(=\lambda)^{n} \\
& \Delta N_{k}^{N d}=N_{k-1}^{N d} \sum_{n=1}^{\infty} \frac{t_{k}^{n}}{n !}\left(-\lambda^{N d}\right)^{n}
\end{aligned}
$$

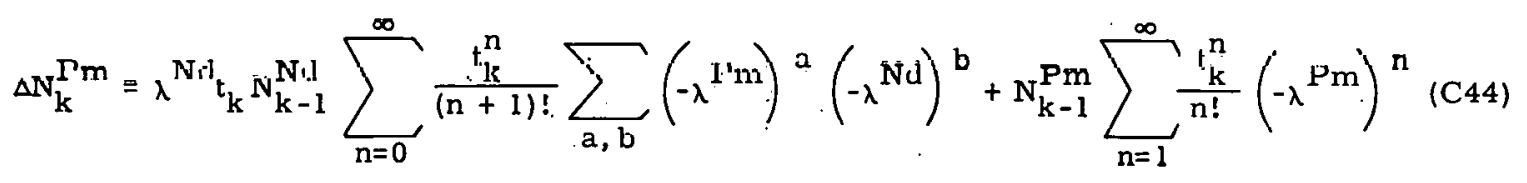

$$
\begin{aligned}
& \Delta N_{k}^{S m}=\left(\lambda^{P m_{t_{k}}}\right)\left(\lambda^{N d_{t_{k}}}\right) N_{k-1}^{N d} \sum_{n=0}^{\infty} \frac{t_{k}^{n}}{(n+2) !} \sum_{a, b}\left(-\lambda^{P m}\right)^{a}(-\lambda)^{b d}-N_{k-1}^{P m} \sum_{n=1}^{\infty} \frac{t_{k}^{n}}{n !}\left(-\lambda{ }^{P m}\right)^{n}
\end{aligned}
$$




\section{APPENDIX D}

\section{MODIFIED FLUX-TIME CODE S0264}

Purpose

This code converts the detailed irradiation history for a particular irradiation sample (the out put of the S0216 Code) into an approximate irradiation history. Such modification is necessary in order to minimize round-off errors in the $\$ 0269$ Code used for isotopic number densities and other quantities derived from these densities. Specifically, a group of steps in the detailed irradiation history of a sample is converted into a single zero-flux step followed by a single nonzero-flux step. The total elapsed time and the total flux-time for all steps in the group are preserved in the conversion to the two equivalent steps.

Input

The output of the S0216 Code, which gives the detailed irradiation history steps, should have $t_{k}$ in seconds in location $951, \phi_{k}$ in neutrons $/ \mathrm{cm}^{2}-\mathrm{sec}$ in location 952 , and $j_{k}$ in location 953 . Inspection of the detailed irradiation history data permits grouping steps of irradiation so that each group corresponds to a total exposure of $3 \times 10^{19} \mathrm{n} / \mathrm{cm}^{2}$. or more (approximately 40 hours in a flux of $2 \times 10^{14} \mathrm{n} / \mathrm{cm}^{2}$-sec). The different charges within a cycle at the MTR frequently comprise suitable groups. Each group is run as a separate problem. The input consists of the group of cards (each containing $t_{k}, \phi_{k}$, and $j_{k}$ ), preceded by a card on which the equivalent thermal flux for the group (usually the maximum flux) is punched in location 852, and the measured epithermal-tothermal flux ratio $\left(\phi_{\mathrm{R}} / \phi\right.$ from the S0226 Code) is punched in location 853 .

Example: Group A (Charge A), Cycle 106

\begin{tabular}{|c|c|c|c|c|c|c|c|}
\hline \multirow{3}{*}{$\begin{array}{l}\text { First } \\
\text { card }\end{array}$} & Quantity & Location No. & & A & $\mathrm{B}$ & $\mathrm{C}$ & \\
\hline & $\phi_{\mathrm{eq}}$ & 852 & +2 & 000 & 000 & 064 & Equivalent thermal flux \\
\hline & $\phi_{\mathrm{R}} / \phi$ & 853 & +5 & 000 & 000 & 048 & $\begin{array}{l}\text { Epithermal-to-thermal } \\
\text { flux ratio }\end{array}$ \\
\hline \multirow{3}{*}{$\begin{array}{l}\text { Cards of } \\
\text { group }\end{array}$} & $t_{k}$ & 951 & +4 & 000 & 000 & 054 & Elapsed time of step \\
\hline & $\phi_{\mathrm{k}}$ & 952 & +1 & 900 & 000 & 064 & Thermal flux of step \\
\hline & $j_{k}$ & 953 & +0 & 000 & 000 & 001 & Index number for step \\
\hline
\end{tabular}

\section{General Comments}

1) One problem consists of one group only.

2) The first input step (951 to 953) of the group must be a zero-flux step (ail zeroes in 952). Otherwise, an unconditional stop will occur with all 9's displayed. The last step should be a nonzero-flux step.

Output

For each input step of the group exclusive of the first, two output cards are punched with four words per card as follows:

Odd cards $\left\{\begin{array}{rlrl}950 & \mathrm{j}= & \text { dimensionless index, the value of } \mathrm{j} \text { on the first input card (zero-flux } \\ & \text { card) } \\ 951 & \mathrm{t}= & \text { equivalent time at zero flux (seconds) } \\ 952 & \phi=0 \\ 953 & \phi_{\mathrm{R}} / \phi= & \text { epithermal-to-thermal flux ratio (same as in 853) }\end{array}\right.$ 
Even cards $\left\{\begin{aligned} \mathbf{j} & =\text { dimensionless index, the value of } \mathbf{j} \text { on the input card most recently } \\ & \text { read } \\ 951 & \mathbf{t}_{\mathrm{eq}}=\text { equivalent time at equivalent flux } \\ 952 & \phi_{\mathrm{eq}}=\text { equivalent thermal flux in } \mathrm{n} / \mathrm{cm}^{2}-\mathrm{sec} \text { (same as in } 852 \text { ) } \\ 953 & \phi_{\mathrm{R}} / \phi=\end{aligned}\right.$

Use of the Output as Input to the S0269 Code

Only the last two output cards are used as input for the S0269 Code. The input deck for the S0269 Code is made up of the last two output cards from the successive groups (described previously and run as separate problems in the $\$ 0264$ code). In the input deck, as now assembled, the first card for a given cycle in the MTR (which will be a zero-flux card) should be repunched so that $j$, in . location 950, contains either 001 or 020 in the C-address. In the S0269 Code, these values of $\mathrm{j}$ will trigger the computation of $\eta$ for either one cooling time (the last of 20 read as input into the 50269 Code) or for all 20 cooling times (from which the transient hehavinr nf $\eta$ is obtained).

The input deck for the S0269 Conde ahnilit he morifien further by romoving the first card (Leive flux card) and placing it at the end of the deck. This will preclude the computation of $\eta$ as a function of cooling time for the case prior to any irradiation and will provide for such computation for the case following the last irradiation. 
Purpose

The S0306 Code is identical to S0269 except that it cannot be used for the initial irradiation step. This code permits computations for later steps in the irradiation history without repeating the earlier steps and may be used for one or more irradiation history steps. Since cross sections and resonance integrals for the various isotopes are read as input, they may be altered in successive problems to account for their variations with concentration or to account for self-shielding.

\section{Instructions}

Code instructions are identical to those of S0269 except for the following:

\begin{tabular}{c} 
Location \\
\hline 267 \\
268 \\
269 \\
270 \\
271 \\
381 \\
382 \\
383
\end{tabular}

\begin{tabular}{cccc}
\multicolumn{4}{c}{ Word in S0269 } \\
\hline-3 & 128 & 001 & 691 \\
+0 & 111 & 009 & 267 \\
-1 & 691 & 692 & 692 \\
+0 & 111 & 008 & 269 \\
+4 & 137 & 000 & 700 \\
+9 & 002 & 703 & 705 \\
+0 & 410 & 700 & 700 \\
+0 & 410 & 705 & 706
\end{tabular}

\begin{tabular}{cccc}
\multicolumn{4}{c}{ Word in S0306 } \\
\hline+0 & 454 & 000 & 000 \\
+0 & 454 & 000 & 000 \\
+0 & 454 & 000 & 000 \\
+0 & 454 & 000 & 000 \\
+0 & 400 & 700 & 700 \\
+0 & 400 & 705 & 706 \\
+0 & 400 & 901 & 903 \\
+0 & 400 & 971 & 976
\end{tabular}

Input

Input cards for locations 001 to 146,151 to $170,700,705$ to 706,901 to 903 , and 971 to 976 must precede the irradiation history cards in locations 950 to 953 . The locations 950 to 953 contain the input for one step in the irradiation history. Successive steps may be run by stacking appropriate input in these locations. Input for 001 to 014 is obtained from the output for the preceding irradiation history step of S0269 (or S0306, depending upon which code was used for the preceding step) in the nearest 197 to 210 locations preceding the last punched 901 output card or cards.* Input for 015 to 018 is obtained from the output of S0269 (or S0306) in the nearest 908 to 911 locations, preceding the last punched 901 output. Input for 019 to 146 is identical to that used in S0269, unless certain adjustments to cross sections or resonance integrals for concentration are to be made as the irradiation history proceeds. Input for locations 151 to 170 is identical to that used in S0269. Input for locations 700 and 705 to 706 is obtained from the first two output cards of S0269. Input for locations 901 to 903 is identical to the last such output of S0269 (or S0306). Input for locations 971 to 976 is identical to the last such output of 50269 (or S0306), and immediately precedes the data in 908 to 911 previously identified.

Output

The output of the S0306 Code is identical to the output of the S0269 Code, except that the first two output cards of S0269 (locations 700 and 705 to 706) are used as input and are not included in the output.

* There may be as many as 20 successive 901 cards. 
The author is indebted to J. J. Scoville for his efforts to obtain the "best" values for the various input parameters used in the code, and to $O$. J. Marlowe for confirming the validity of the series expansions in the expressions for the isotopic number density in Appendix $C$ and for deriving the recursion relations necessary for the code calculation of these expansions. Thanks are also due to J. C. Connor and E. D. McGarry for numerous stimulating discussions.

\section{REFERENCES}

1. S. B. Gunst, "Reactivity Associated with the Decay of $\mathrm{Np}^{239}$ in Irradiated Natural Uranium," (to be published).

2. D. R. de Boisblanc, et al., "The Reactivity Measurement Facility and Its Applications, " 2nd U. N. Inter. Conf. on the Peaceful Uses of Atomic Energy, A/Conf/15/P/1842, (1958). 